\title{
Meltwater generation in ice stream shear margins: case
}

\section{study in Antarctic ice streams}

\author{
Meghana Ranganathan ${ }^{1}$, Jack-William Barotta ${ }^{2,3}$, Colin R. Meyer ${ }^{4}$, Brent Minchew ${ }^{1}$ \\ ${ }^{1}$ Department of Earth, Atmospheric and Planetary Sciences, Massachusetts Institute of Technology, \\ Cambridge, MA, USA \\ 2 Department of Mathematics, Massachusetts Institute of Technology, Cambridge, MA, USA \\ ${ }^{3}$ School of Engineering, Brown University, Providence, RI, USA \\ ${ }^{4}$ Thayer School of Engineering, Dartmouth College, Hanover, NH, USA \\ Correspondence: Meghana Ranganathan <meghanar@mit.edu>
}

\begin{abstract}
.
Liquid water within glacier ice and at the glacier beds exerts a significant control on ice flow and glacier stability through a number of processes, including altering the rheology of the ice and lubricating the bed. Some of this water is generated as melt in regions of rapid deformation, including shear margins, due to heating by viscous dissipation. However, how much meltwater is generated and drained from shear margins remains unclear. Here, we apply a model that describes the evolution of ice temperature, melting, and water transport within deforming ice to estimate the flux of meltwater from shear margins in glaciers. We derive analytical expressions for ice temperature, effective pressure, and porosity in zones of temperate ice, and we apply this model to estimate the flux from three Antarctic glaciers: Bindschadler and MacAyeal Ice Streams, Pine Island Glacier, and Byrd Glacier. We show that the flux of meltwater from shear margins in these regions may be as significant as the meltwater produced by frictional heating at the bed, with average fluxes of $\sim 1000-2000 \mathrm{~m}^{3} \mathrm{yr}^{-1}$. This contribution of shear heating to meltwater flux at the bed may thus affect both the rheology of the ice as well as sliding at the bed, both key controls on fast ice flow.
\end{abstract}

\section{INTRODUCTION}

Fast-flowing glaciers and ice streams drain a significant fraction of the Greenland and Antarctic ice sheets (Rignot and others, 2011; Joughin and others, 2018a,b; Lemos and others, 2018) and many of the glaciers have been accelerating in the last two decades, contributing more to sea-level rise (De Rydt and others, 2021; King and others, 2020). The speed of flow in many ice streams are largely controlled by friction at the bed (the ice-sediment interface) and lateral shear stresses in the margins (MacAyeal and others, 
1995; Morlighem and others, 2013; Ranganathan and others, 2021a). Many of these ice streams flow over complex hydrologic systems that transport water at the glacier bed to the ocean (Engelhardt and Kamb, 1997; Fricker and others, 2007, 2010, 2016; Siegfried and Fricker, 2021), and the presence of liquid water in glaciers and in these channels affects both basal friction and lateral shear stresses in the margins. The amount and distribution of water at the bed alters the basal friction of glaciers, as water acts as a lubricant and changes the characteristics of the sediments the ice slides over, thereby affecting the speed of flow (Tulaczyk and others, 2000a; Iverson and Iverson, 2001; Price and others, 2008; Hoffman and others, 2011). In some regions, water collects into subglacial lakes which may store significant amounts of water. Observations have shown subglacial floods to cause acceleration of glaciers, ultimately affecting the amount of ice discharge (Stearns and others, 2008; Howat and others, 2013; Livingstone and others, 2013; Siegfried and others, 2016). Whether meltwater is held within the ice or drained to the bed also may affect the rheology of ice in the margins by softening the ice (Barnes and others, 1971; De La Chapelle and others, 1999; Dash and others, 2006; Adams and others, 2021) and partially set the width of ice streams that are not topographically controlled (Haseloff and others, 2019). Additionally, meltwater generation on ice shelves may enable flux of freshwater to the ocean, affecting ocean circulation and the ice-ocean interface which may control ice shelf stability (Alley and others, 2016). Therefore, meltwater has a significant effect on the flow speed and stability of rapidly-deforming glaciers.

NASA's Ice, Cloud, and Land Elevation Satellite (ICESat) enabled observation of glacier hydrology, including distribution of subglacial lakes and hydrologic networks (Fricker and others, 2007) and estimates of and changes to water volume (Fricker and others, 2010; McMillan and others, 2013; Siegfried and others, 2014; Smith and others, 2017; Siegfried and Fricker, 2021). While observations have improved our understanding of how the subglacial hydrologic system is changing and affecting glacier flow, a characterization of the physical processes generating the water in these systems remains incomplete and is necessary for projections of subglacial hydrology and its future effects on fast flow given a changing climate.

In Antarctica, much of the water in the subglacial hydrologic system is generated at the glacier bed (through melting by geothermal heat and basal friction), while in Greenland, most of the water is generated by surface melt due to warm temperatures. However, some meltwater percolates from the glacier itself, either through moulins or through small veins in temperate ice (Lliboutry, 1971). This temperate ice is usually created through shear heating (work done during rapid ice deformation being dissipated as heat) and is generally found in regions of significant shear, such as the base of ice sheets where the ice is frozen to the bed and in the margins of ice streams (Jacobson and Raymond, 1998; Schoof, 2004; Suckale and others, 2014; Perol and Rice, 2015; Marsh and others, 2016). In particular, previous work has found potentially extensive temperate zones in the margins of Antarctic ice streams due to the rapid deformation in these regions (Perol and others, 2015; Meyer and Minchew, 2018). Since temperate ice is porous, meltwater generated in temperate zones can percolate through the temperate zone and eventually drain into the hydrologic channels at the bed (Lliboutry, 1971; Perol and Rice, 2015; Meyer and others, 2018). The contribution of temperate ice zones generated by shear heating to meltwater production, however, is currently poorly characterized.

Here, we develop and apply a model for the flux of meltwater out of temperate ice zones in order to quantify the contribution of shear heating to subglacial hydrologic channels. We use an ice temperature model derived by Meyer and Minchew (2018) from conservation of energy to identify the thickness of temperate zones. We then apply the thickness of the temperate zone to a model for polythermal glaciers developed by Schoof and Hewitt (2016), which estimates meltwater drainage from ice porosity and pressure gradients. We apply this coupled model to the one-dimensional case of a vertical ice column in steady-state and show that our analytical formulation matches with numerical solutions to the conservation of energy and water transport equations. Finally, we apply this model and remotely sensed observations to estimate the meltwater flux out of shear margins of the Antarctic Ice Sheet. 


\section{MODEL FOR EFFECTIVE PRESSURE, POROSITY, AND MELTWATER FLUX}

We develop a model for temperature and meltwater flux in shear margins of ice streams. We assume that, in shear margins of ice streams, vertical shear can be neglected and lateral shear is the primary form of deformation, as done in previous studies [e.g. Perol and Rice (2015); Meyer and Minchew (2018)]. Heat is introduced into ice primarily through frictional heat at the bed, geothermal heat at the bed, and ice deformation internally. Heat is then diffused and advected both laterally and vertically. In areas where there is enough heat to bring the ice up to its melting point, a temperate zone is generated. Temperate ice is defined as a mixture of ice and liquid meltwater that is at the pressure melting temperature. In this study, we use a fixed melting temperature of $T_{m}=273 \mathrm{~K}$, the pressure melting point of ice at approximately atmospheric pressure conditions. We neglect the effects of varying pressure on the melting temperature, a reasonable assumption given that the melting temperature of ice varies by less than $2 \mathrm{~K}$ at pressures expected in ice sheets, which is within the uncertainties of our model. Temperate ice is porous, with dimensional porosity $\tilde{\phi}$ that is affected by a melting rate $m$. We approximate ice in temperate zones as incompressible, recognizing that porosity will make temperate ice slightly compressible (Hewitt and Schoof, 2017). The heat and moisture equations are defined, respectively, as:

$$
\begin{aligned}
& \rho_{I} c_{p}\left[\frac{\partial \tilde{T}}{\partial \tilde{t}}+\underline{\mathrm{u}} \cdot \nabla \tilde{T}\right]-\nabla \cdot(K \nabla \tilde{T})=W-\rho_{w} \mathcal{L} m \\
& \frac{\partial \tilde{\phi}}{\partial \tilde{t}}+\underline{\mathrm{u}} \cdot \nabla \tilde{\phi}+\nabla \cdot \underline{\tilde{\mathbf{J}}}=m
\end{aligned}
$$

where $\tilde{T}$ is dimensional ice temperature $\left(\tilde{T} \leqslant T_{m}\right)$, $\underline{u}$ is ice velocity, $\rho_{I}$ is the mass density for ice, $c_{p}$ is the specific heat capacity of ice, $K$ is thermal conductivity, $\rho_{w}$ is the mass density of water, $\mathcal{L}$ is the specific latent heat of fusion, $\tilde{J}$ is the dimensional water flux, and $W=\sigma_{i j} \dot{\varepsilon}_{i j}$ is the rate of heating through viscous dissipation (hereafter called shear heating, where $\sigma_{i j}$ is the deviatoric stress tensor and $\dot{\varepsilon}_{i j}$ is the strain-rate tensor). Applying the constitutive relation for ice, $W$ can be written as $W=A^{-\frac{1}{n}} \dot{\varepsilon}^{\frac{n+1}{n}}$, where $\dot{\epsilon}=\sqrt{\frac{1}{2} \dot{\epsilon}_{i j} \dot{\epsilon}_{i j}}$ is the effective strain rate and $A$ is the ice softness parameter which is inversely proportional to ice viscosity $\eta_{I}$ such that $2 \eta_{I}=A^{-1 / n} \dot{\varepsilon}^{(1-n) / n}$.

We will use these governing equations to estimate the flux of water out of temperate ice zones $(\tilde{J})$. To do so, we redefine Equations (1a) and (1b) in terms of enthalpy $\tilde{\mathcal{H}}$, a term that defines the internal energy of the system along with its pressure and volume and which is particularly useful for multiphase fluid flow. We define enthalpy as

$$
\tilde{\mathcal{H}}=\rho_{I} c_{p}\left(\tilde{T}-T_{m}\right)+\rho_{w} \mathcal{L} \tilde{\phi}
$$

where $T_{m}$ is the constant melting temperature. We assume mass conservation $\frac{\partial \tilde{\rho}}{\partial t}+\nabla \cdot(\tilde{\rho} \underline{u})=0$, in which $\tilde{\rho}=(1-\tilde{\phi}) \rho_{I}$ and $\rho_{I}$ is a constant. Applying this, Equations 1a and $1 \mathrm{~b}$ can be combined as

$$
\frac{\partial \tilde{\mathcal{H}}}{\partial \tilde{t}}+\underline{u} \cdot \nabla \tilde{\mathcal{H}}-\nabla \cdot(K \nabla \tilde{T})=W-\rho_{w} \mathcal{L}(\nabla \cdot \underline{\tilde{J}})
$$

We define meltwater flux $\underline{\tilde{J}}$ using Darcy's Law, a model for fluid flow through a porous medium due to gravitational body forces and the gradient of effective pressure, as 


$$
\underline{\tilde{J}}=\frac{k_{0} \tilde{\phi}^{\alpha}}{\eta_{w}}\left[\left(\rho_{w}-\rho_{I}\right) \mathrm{g}+\nabla \tilde{N}\right]
$$

where $k_{0}$ is the coefficient of hydraulic permeability, $\alpha$ is the porosity exponent that sets the dependence of hydraulic diffusion on porosity, $\eta_{w}$ is the water viscosity, $\mathrm{g}=(0,0, g)$ is gravity (positive vertically), and $\tilde{N}$ is dimensional effective pressure, defined as the difference between the pressure in the ice and pore water pressure. We can relate this pressure difference to the rate of ice compaction such that

$$
\tilde{N}=-\frac{\eta_{I}}{\tilde{\phi}} \nabla \cdot \underline{\mathrm{u}}
$$

in which $\frac{\eta_{I}}{\tilde{\phi}}$ acts as a bulk ice viscosity and $\eta_{I}$ is ice viscosity (Schoof and Hewitt, 2016; Meyer and others, 2018). If we assume incompressibility and mass conservation, this can be rewritten as $\tilde{N}=\frac{\eta_{I}}{\tilde{\phi}} \nabla \cdot \underline{\tilde{J}}$. We can thus re-express Equations (3) and (4) as coupled equations:

$$
\begin{array}{r}
\frac{\partial \tilde{\mathcal{H}}}{\partial \tilde{t}}+\underline{\mathrm{u}} \cdot(\nabla \tilde{\mathcal{H}})-\nabla \cdot(K \nabla \tilde{T})=W-\rho_{w} \mathcal{L}\left(\frac{\phi \tilde{N}}{\eta_{I}}\right) \\
\nabla \cdot\left[\frac{k_{0} \tilde{\phi}^{\alpha}}{\eta_{w}}\left[\left(\rho_{w}-\rho_{I}\right) \mathrm{g}+\nabla \tilde{N}\right]\right]=\frac{\tilde{\phi} \tilde{N}}{\eta_{I}}
\end{array}
$$

Equations (6a) and (6b) represent a general, three-dimensional model for the evolution of temperature, effective pressure, and porosity in temperate ice. For this study, following previous work, we assume that horizontal advection is negligible, horizontal thermal diffusion is negligible, thermal conductivity $K$ is constant with depth, and there is no melting at the ice surface (Perol and Rice, 2015; Schoof and Hewitt, 2016; Meyer and Minchew, 2018). Therefore, Equations 6a and 6b can be written in a one-dimensional formulation as

$$
\begin{aligned}
& \frac{\partial \tilde{\mathcal{H}}}{\partial \tilde{t}}+a \frac{\partial \tilde{\mathcal{H}}}{\partial \tilde{z}}-K \frac{\partial^{2} \tilde{T}}{\partial \tilde{z}^{2}}=W-\rho_{w} \mathcal{L}\left(\frac{\tilde{\phi} \tilde{N}}{\eta_{I}}\right) \\
& \frac{\partial}{\partial \tilde{z}}\left\{\frac{k_{0} \tilde{\phi}^{\alpha}}{\eta_{w}}\left[-\left(\rho_{w}-\rho_{I}\right) g+\frac{\partial \tilde{N}}{\partial \tilde{z}}\right]\right\}=\frac{\tilde{\phi} \tilde{N}}{\eta_{I}}
\end{aligned}
$$

where $a$ is rate of ice accumulation. For simplicity moving forward, we non-dimensionalize Equations (7a) and (7b). To do so, we define scales for enthalpy $\tilde{\mathcal{H}}$, height $\tilde{z}$, ice temperature $\tilde{T}$, porosity $\tilde{\phi}$, effective pressure $\tilde{N}$, time $\tilde{t}$, and meltwater flux $\tilde{J}$ based on ice thickness $h$, specific heat capacity of ice $c_{p}$, mass density of ice $\rho_{I}$, a scale for ice viscosity $\left[\eta_{I}\right]$, thermal conductivity $K$, the difference between melting temperature and surface temperature $\Delta T=T_{m}-T_{s}$, and latent heat of fusion $\mathcal{L}$. These nondimensionalizations are defined as 


$$
\begin{array}{lr}
\tilde{\mathcal{H}}=[\mathcal{H}] \mathcal{H} & {[\mathcal{H}]=\rho_{I} c_{p} \Delta T} \\
\tilde{z}=h z & \\
\tilde{T}=[T] T+T_{m} & {[T]=\Delta T} \\
\tilde{\phi}=\epsilon \phi & \epsilon=\frac{\rho_{I} c_{p} \Delta T}{\rho_{w} \mathcal{L}} \\
\tilde{N}=[N] N & {[N]=\frac{\left[\eta_{I}\right] K \Delta T}{\epsilon \rho_{w} \mathcal{L} h^{2}}} \\
\tilde{t}=[t] t & {[t]=\frac{h^{2} \rho_{I} c_{p}}{K}} \\
\tilde{J}=[J] J & {[J]=\frac{K \Delta T}{\rho_{w} \mathcal{L} h}}
\end{array}
$$

such that $\mathcal{H}, z, T, \phi, N, t, J$ are dimensionless. The full nondimensionalization is presented in Appendix A, and the resulting non-dimensionalized versions of Equations $7 \mathrm{a}$ and $7 \mathrm{~b}$ are

$$
\begin{gathered}
\frac{\partial \mathcal{H}}{\partial t}+\operatorname{Pe} \frac{\partial \mathcal{H}}{\partial z}-\frac{\partial^{2} T}{\partial z^{2}}=\mathrm{Br}-\phi N \\
\frac{\partial}{\partial z}\left\{\kappa \phi^{\alpha}\left[-1+\delta \frac{\partial N}{\partial z}\right]\right\}=\phi N
\end{gathered}
$$

defined as a function of the nondimensional numbers:

$\mathrm{Br}=\frac{W h^{2}}{K \Delta T}$, the ratio of the rates of shear heating to thermal conduction

$\mathrm{Pe}=\frac{a H \rho_{I} c_{p}}{K}$, the ratio of advection of cold ice to thermal diffusion

$\delta=\frac{[N]}{h\left(\rho_{w}-\rho_{I}\right) g}$, the contribution of effective pressure to moisture flux

$\kappa=\frac{k_{0} \rho_{I} c_{p} \epsilon^{\alpha-1}\left(\rho_{w}-\rho_{I}\right) g}{K \eta_{w}}$, the ratio of heat advected in the meltwater to thermal diffusion in the ice

In this work, we seek to find a steady-state solution, as done in Hewitt and Schoof (2017), and in future work will expand to consider time-dependent solutions. The steady-state forms of Equations $9 \mathrm{a}$ and $9 \mathrm{~b}$ are

$$
\begin{aligned}
& \operatorname{Pe} \frac{\partial \phi}{\partial z}=\mathrm{Br}-\phi N \\
& \operatorname{Pe} \frac{\partial T}{\partial z}=\frac{\partial^{2} T}{\partial z^{2}}+\mathrm{Br} \\
& \frac{\partial}{\partial z}\left\{\kappa \phi^{\alpha}\left[-1+\delta \frac{\partial N}{\partial z}\right]\right\}=\phi N
\end{aligned}
$$

Equation (10b) is solved analytically as in Meyer and Minchew (2018), with the important assumption that ice viscosity is constant with depth. This assumption is discussed further in the Discussion section.

The parameter $\delta$ is small, and therefore at first order, we would like to neglect the term $\delta \frac{\partial N}{\partial z}$, but this 
is a singular perturbation (Holmes, 2013). Therefore considering the higher-order terms is necessary. We derive asymptotic solutions to Equations 10a and 10c in both the outer layer (above the boundary layer; we define this solution as the outer solution) and the inner layer (within the boundary layer; we define this solution as the inner solution). We find the outer and inner solutions for both effective pressure and ice porosity.

\section{Outer Solutions}

Since the boundary layer thickness is defined through $\delta$, to find a solution far from the boundary layer, we neglect the terms with the highest order of $\delta$. For the outer solution of porosity, we substitute Equation (10a) into Equation (10c), with the condition that porosity must be zero at the boundary between cold ice and temperate ice $\left(\phi\left(z_{c t}\right)=0\right.$, where $z_{c t}$ is the depth of the top of the temperate zone):

$$
\operatorname{Pe} \frac{\partial \phi}{\partial z}=\operatorname{Br}+\frac{\partial}{\partial z}\left[\kappa \phi^{\alpha}\right]
$$

Integrating over depth and applying the boundary condition on porosity, we have

$$
\operatorname{Pe} \phi-\kappa \phi^{\alpha}=\operatorname{Br}\left(z-z_{c t}\right)
$$

To find the outer solution of effective pressure, we solve Equation (10a) for $\frac{\partial \phi}{\partial z}$ and insert into Equation (10c). When rearranged, this becomes

$$
N_{\text {outer }}=-\frac{\operatorname{Br} \kappa \alpha \phi^{\alpha-2}}{\operatorname{Pe}-\kappa \alpha \phi^{\alpha-1}}
$$

When solved, Equations (12) and (13) give us the solutions for effective pressure and porosity away from the basal boundary. Equation (13) can be solved analytically and we solve Equation (12) numerically with an iterative nonlinear equation solver.

\section{Inner Solutions}

To find the solutions within the boundary layer, we rescale dimensionless height $\tilde{z}$ by a factor of $\delta^{\beta}$ to obtain a scaled height $\hat{z}$

$$
z=\delta^{\beta} \hat{z}
$$

which allows us to zoom into the boundary layer. To find $\beta$, we assume that the dimensionless groups of Equations (10a), (10b), and (10c) are all $\mathcal{O}(1)$. The largest power of $\delta$ is $\frac{1}{\delta^{\beta}} \frac{\partial}{\partial \hat{z}}\left[\delta^{1-\beta} \frac{\partial N}{\partial \hat{z}}\right]$, which is $\mathcal{O}\left(\delta^{1-2 \beta}\right)$. So if we let $1-2 \beta=0, \beta=\frac{1}{2}$. Taking only $\mathcal{O}(1)$ and $\mathcal{O}\left(\delta^{\frac{1}{2}}\right)$ terms, Equations (10a) and (10c) can be rewritten as

$$
\begin{aligned}
& \operatorname{Pe} \frac{\partial \phi}{\partial \hat{z}}=\delta^{\frac{1}{2}}(\mathrm{Br}-\phi N) \\
& \frac{\partial}{\partial \hat{z}}\left\{\kappa \phi^{\alpha}\left[-1+\delta^{\frac{1}{2}} \frac{\partial N}{\partial \hat{z}}\right]\right\}=\delta^{\frac{1}{2}} \phi N
\end{aligned}
$$


$\phi_{\text {inner }}$ can be expanded in the form $\phi_{\text {inner }}(\hat{z})=\phi_{0}(\hat{z})+\delta^{\frac{1}{2}} \phi_{1}(\hat{z})+\mathcal{O}(\delta)$. Approximating the solution to first order in $\delta^{\frac{1}{2}} \phi_{1}(\hat{z})$, we plug this expansion into Equations (15a) and (15b):

$$
\begin{aligned}
& \operatorname{Pe}\left[\frac{\partial \phi_{0}}{\partial \hat{z}}+\delta^{\frac{1}{2}} \frac{\partial \phi_{1}}{\partial \hat{z}}\right]=\delta^{\frac{1}{2}}\left[\mathrm{Br}-\phi_{0} N\right] \\
& \frac{\partial}{\partial \hat{z}}\left\{\kappa\left(\phi_{0}+\delta^{\frac{1}{2}} \phi_{1}\right)^{\alpha}\left[-1+\delta^{\frac{1}{2}} \frac{\partial N}{\partial \hat{z}}\right]\right\}=\delta^{\frac{1}{2}} \phi_{0} N
\end{aligned}
$$

Thus the zeroth and first order equations and solutions for Equation (16a) are

$$
\begin{array}{r}
\mathcal{O}(1): \operatorname{Pe} \frac{\partial \phi_{0}}{\partial \hat{z}}=0 \\
\mathcal{O}\left(\delta^{\frac{1}{2}}\right): \frac{\partial \phi_{1}}{\partial \hat{z}}=\frac{\mathrm{Br}-\phi_{0} N_{\text {inner }}}{\mathrm{Pe}}
\end{array}
$$

Since, from Equation $17 \mathrm{a}, \phi_{0}$ is a constant in the boundary layer, it must be that $\phi_{0}=\phi_{\text {outer }}(0)$, where $\hat{z}=0$ is at the bed to ensure matching between the inner and outer solutions. Equation (17b) is solved after finding an expression for the inner solution of $\tilde{N}$. To find this, we consider Equation (16b). As only the first order solution for effective pressure is necessary, we only take terms of $\mathcal{O}\left(\delta^{\frac{1}{2}}\right)$. Substituting Equation (17b) into Equation (16b), we obtain

$$
\frac{\partial^{2} N}{\partial \hat{z}^{2}}=\left[\frac{\mathrm{Pe}-\kappa \alpha \phi_{0}^{\alpha-1}}{\operatorname{Pe} \kappa \phi_{0}^{\alpha}}\right] \phi_{0} N+\frac{\alpha \phi_{0}^{\alpha-1} \mathrm{Br}}{\operatorname{Pe} \phi_{0}^{\alpha}}
$$

After applying the boundary condition of $N(\hat{z}=0)=N_{0}$, the inner solution for effective pressure is

$$
\begin{array}{r}
N_{\text {inner }}=N_{\text {outer }}(0)+\left(N_{0}-\right. \\
a=\sqrt{\frac{\operatorname{Pe}-\kappa \alpha \phi_{0}^{\alpha-1}}{\operatorname{Pe} \kappa \phi_{0}^{\alpha}} \phi_{0}}
\end{array}
$$

Equation (19a) can then substituted into Equation (17b) and then Equation (17b) integrated to find the first order solution for porosity $\phi_{1}$. To find the constant of integration $C$, we use the higher-order matching condition $\lim _{\hat{z} \rightarrow \infty} \delta^{\beta} \phi_{1}(\hat{z})=\lim _{z \rightarrow 0} \phi_{\text {outer }}(z)$ to find that $C=0$ (full description in Appendix B). Thus, the full inner solution for porosity is

$$
\phi_{\text {inner }}=\phi_{\text {outer }}(0)+\delta^{\frac{1}{2}}\left[\left[\frac{\mathrm{Br}-\phi_{0} N_{\text {outer }}(0)}{\mathrm{Pe}}\right] \hat{z}+\frac{\phi_{0}}{\sqrt{a} \mathrm{Pe}}\left[N_{0}-N_{\text {outer }}(0)\right] \exp [-\sqrt{a} \hat{z}]\right]
$$

\section{Composite Solutions and Meltwater Flux}

To find a solution for meltwater flux that is valid both in and out of the boundary layer, we seek composite solutions for effective pressure and porosity which combines the inner and outer solutions. To do so, we add the outer and inner solutions and subtract the overlap (Bender and Orszag, 1999; Holmes, 2013). The full derivation is in Appendix C, resulting in the following composite solutions: 


$$
\begin{array}{r}
N_{\text {composite }}=N_{\text {outer }}+\left(N_{0}-N_{\text {outer }}(0)\right) \exp (-\sqrt{a} \hat{z}) \\
\phi_{\text {composite }}=\phi_{\text {outer }}+\phi_{\text {inner }}-\left[\phi_{\text {outer }}(0)+\frac{z}{z_{c t}}\left[-\frac{\mathrm{Br} z_{c t}}{\kappa \alpha \phi_{0}^{\alpha-1}-\mathrm{Pe}}\right]\right]
\end{array}
$$

These are solutions for $N$ and $\phi$ that are valid for the full temperate zone. We can then plug these solutions into a one-dimensional form of Equation (4) to find the resulting meltwater flux out of the temperate zone:

$$
J=\kappa \phi_{\text {composite }}^{\alpha}\left[-1+\delta \frac{\partial N_{\text {composite }}}{\partial z}\right]
$$

In the following sections, we will use Equations (21a), (21b), and (22) to estimate effective pressure, porosity, and flux (respectively) in an idealized set-up, in order to determine the sensitivity of flux estimates to various parameters, and then in Antarctic ice streams, to make inferences about Antarctic ice dynamics.

\section{Comparison of Analytical Expressions with Numerics}

To benchmark our estimates, we compare our analytical expressions with results from a numerical model that solves Equations (7a) and (7b) in a finite volume implementation with a mesh of $d z=\frac{h}{256}$ and where steady state is defined such that the sum of squares of differences between iterations is less than $10^{-8}$. The full numerical model is described in Meyer and others (2018). By the principles of asymptotics, the outer solution should be valid above the boundary layer (defined by the variable $\delta$ ) and the inner solution should be valid within the boundary layer. The composite solution should be valid at all heights.

In this section, for consistency with the parameters in the numerics, we set $\mathrm{Br}=22.5$ and set $\delta=0.0023$ for a 200 meter thick ice column. For the remainder of the study, the parameter values are those presented in Table 1. This rate of shear heating and ice thickness results in a temperate zone forming at $\sim 68 \%$ of the ice thickness (Figure 1a). For effective pressure and porosity, the analytical expressions follow the numerics closely. Effective pressure is large at the cold/temperate boundary $\left(z_{c t}\right)$ and decreases approximately linearly as it gets closer to the boundary layer. At the boundary layer, effective pressure begins to decrease exponentially (Figure 1b). Porosity, on the other hand, is zero at the cold/temperate boundary and increases approximately linearly until the boundary layer, at which point it increases with a linear and an exponential term (Figure 1c). The composite solutions for pressure and porosity follow the outer solution above the boundary layer and the inner solution within the boundary layer. The flux of meltwater out of the temperate zone increases down the ice column, with $q(0)=-9.47$ (Figure 1d). Since the flux at the bed computed by numerics is $q=-9.67$, our analytical estimate carries a small $(\sim 2 \%)$ error. Comparison to numerical estimates for another rate of shear heating is presented in the Supplement to demonstrate the generality of the matching between analytics and numerics.

\section{Dependence of Results on Parameters}

The estimates presented here are affected by uncertain parameters, in particular the basal boundary condition for effective pressure $N_{0}$, the porosity exponent $\alpha$, the nondimensional ratio of heat advected in meltwater to heat diffused in ice $\kappa$, the nondimensional number representing the thickness of the basal boundary layer $\delta$, and the nondimensional numbers that affect rates of shear heating and its effect on ice temperature $\mathrm{Br}$, Pe. While $\mathrm{Br}$ and $\mathrm{Pe}$ can be estimated from observations, the remaining parameters carry significant uncertainties. 

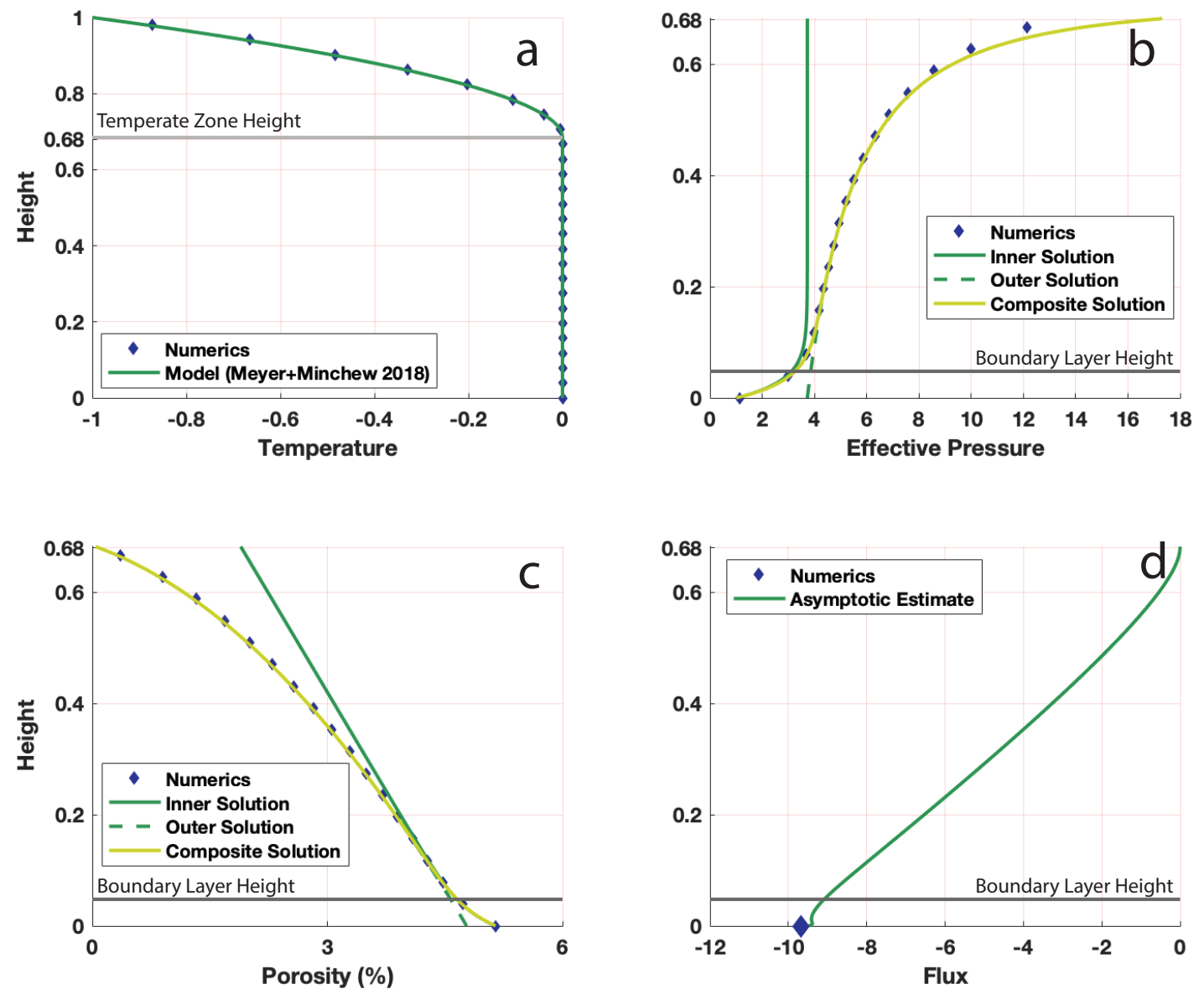

Fig. 1. Ice temperature, effective pressure, porosity, and meltwater flux, compared to numerics. In comparison to numerics, we let $H=200, \mathrm{Pe}=-1.1115, \kappa=0.4416, \mathrm{Br}=22.4919, \delta=0.0023, \alpha=2, \Delta T=1, N_{0}=1$. 
(a) Brinkman Number
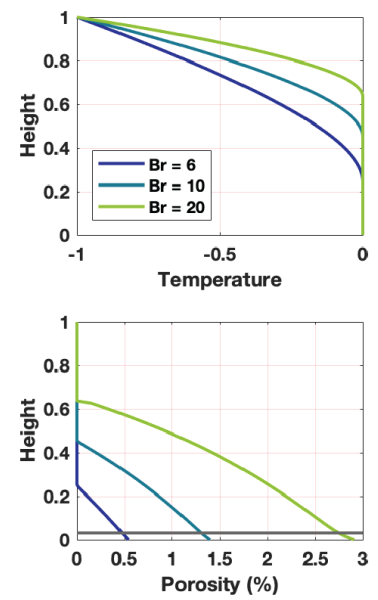

(c) $\mathbf{N}_{\mathbf{0}}$
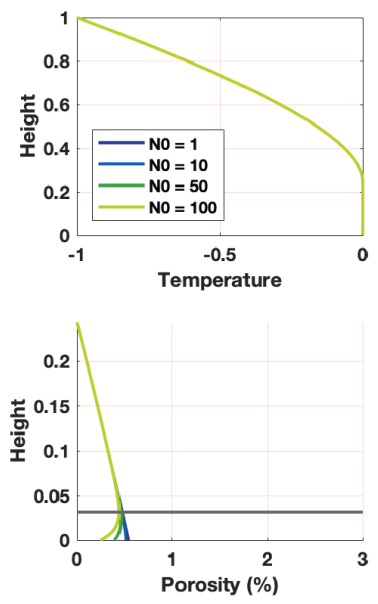

(e) Brinkman and Peclet Numbers
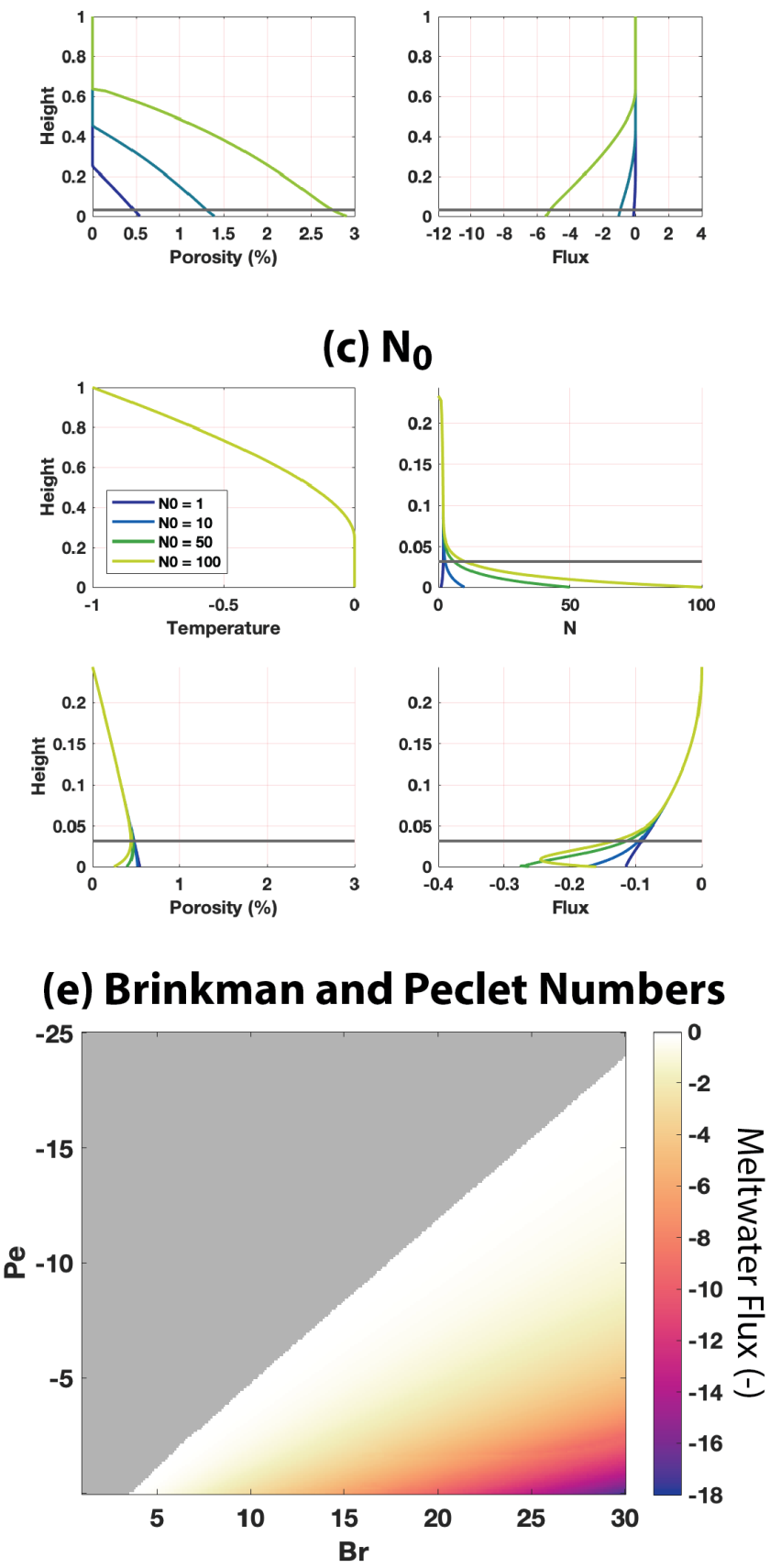

(b) $\mathrm{K}$
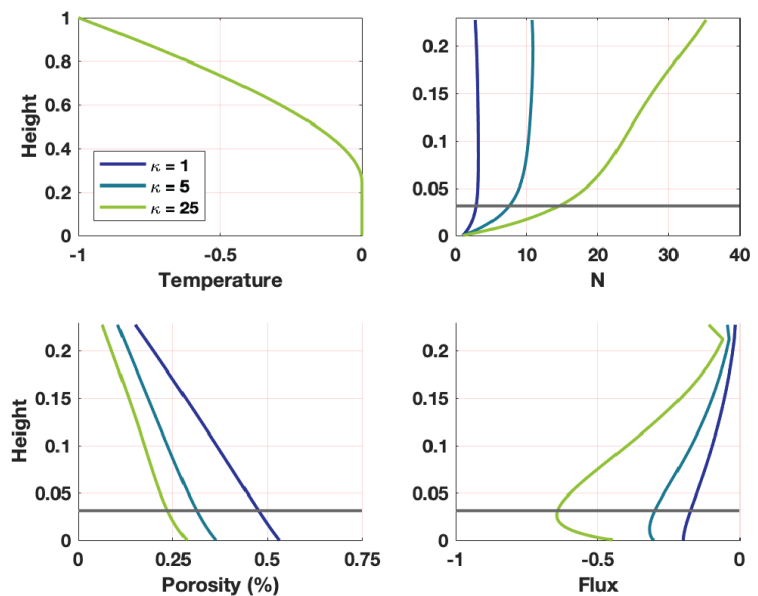

(d) $a$
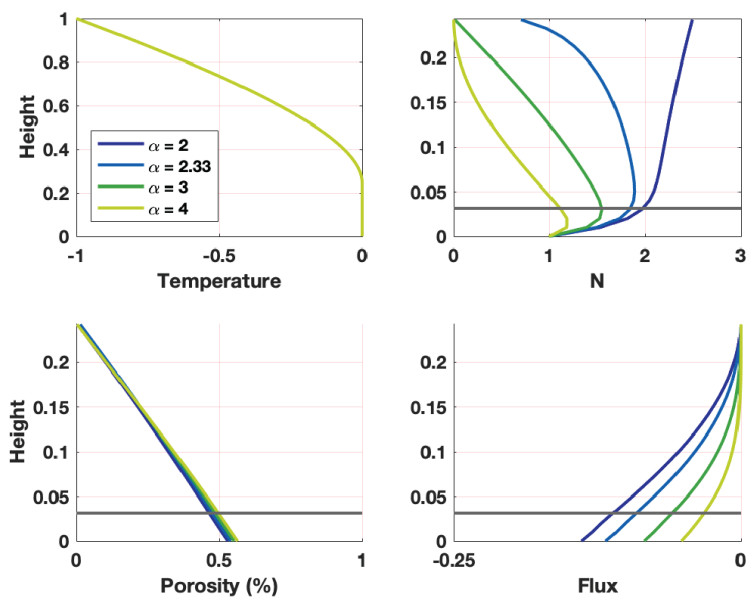

(f) $\mathrm{K}$ and $\mathbf{a}$

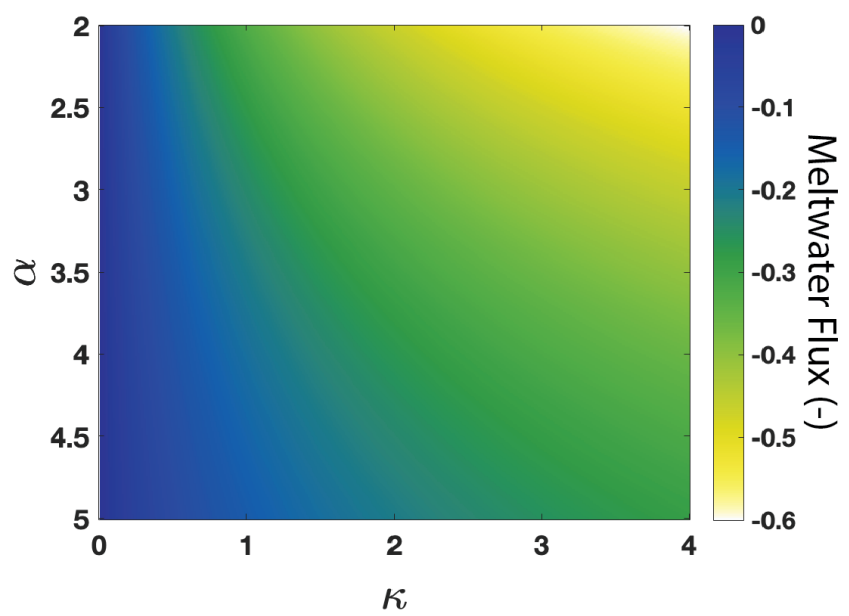

Fig. 2. Ice temperature, effective pressure, porosity, and meltwater flux, computed with varying parameters. The standard parameters are $h=1000 \mathrm{~m}, \mathrm{Pe}=-2.5, \kappa=0.52, \mathrm{Br}=6, \delta=0.001, \alpha=2.5, \Delta T=25 \mathrm{~K}, N_{0}=1$, and then specific parameters are varied: (a) $\mathrm{Br}$, (b) $\kappa$, (c) $N_{0}$, (d) $\alpha$, (e) $\mathrm{Br}$ and $\mathrm{Pe}$, (f) $\kappa$ and $\alpha$. 
The parameters $\kappa$ and $\alpha$ represent the permeability of glacier ice. Their exact values are uncertain (Figure 2b,d,f). The porosity exponent $\alpha$ likely lies between $\alpha=2$ and $\alpha=3$, consistent with a KozenyCarman model of permeability (Nye and Frank, 1973; Hewitt and Schoof, 2017). We define $\alpha=2.33$, in line with Schoof and Hewitt (2016). We let $\kappa=0.52$, a value such that the permeability constant $k_{0}=10^{-12}$ $\mathrm{m}^{2}$, in line with Hewitt and Schoof (2017). Larger values of $\kappa$ and $\alpha$ result in somewhat larger meltwater flux estimates, though the flux is not very sensitive to either parameter and is more sensitive to $\kappa$ than to $\alpha$. An increase in $\kappa$ of 1 results in a change in meltwater flux of $\sim 5 \mathrm{~m}^{3} \mathrm{yr}^{-1}$. Changing the value of $\alpha$ by 1 results in a change in meltwater flux of $\sim 3 \mathrm{~m}^{3} \mathrm{yr}^{-1}$.

We chose the basal boundary condition $N_{0}=20 \mathrm{kPa}$ to approximate estimates of basal shear stress from inversions (Joughin and others, 2004; Morlighem and others, 2013; Ranganathan and others, 2021a). The choice in $N_{0}$ does affect the flux, since higher effective pressure at the bed causes compaction and reduces flux out of the temperate zone (Figure 2c). Therefore, if the true effective pressure was greater than $20 \mathrm{kPa}$, we would expect a reduced flux, and if less than $20 \mathrm{kPa}$, we would expect an increased flux. A change in effective pressure of $\sim 2 \mathrm{kPa}$ translates to a flux difference of $\sim 3 \mathrm{~m}^{3} \mathrm{yr}^{-1}$. This suggests that uncertainties in $N_{0}$ likely leads to uncertainties in our flux estimates of $\leqslant 100 \mathrm{~m}^{3} \mathrm{yr}^{-1}$, or between $1-10 \%$ of the estimates.

The nondimensional number $\delta$ physically represents the contribution of compaction to meltwater flux, and it directly relates to the thickness of the basal boundary layer by $\delta^{\frac{1}{2}} \tilde{z}$ being the nondimensional height of the boundary layer. We choose $\delta=0.001$ such that the boundary layer is $\sim 3 \%$ of the ice thickness, representing a region close to the bed. Schoof and Hewitt (2016) chooses $\delta=0.02$, in which the boundary layer is $\sim 14 \%$ of the ice thickness. In the Supplement, we evaluate the sensitivity of our estimates to the choice of $\delta$ value. A value of $\delta$ an order of magnitude larger than we use here $(\delta=0.01$; similar to the value used in Schoof and Hewitt (2016)) yields a difference in flux of $0.5 \mathrm{~m}^{3} \mathrm{yr}^{-1}$. A value of $\delta$ two orders of magnitude larger $(\delta=0.1)$ would result in a difference in flux estimate of $\sim 3 \mathrm{~m}^{3} \mathrm{yr}^{-1}$. Since $\delta=0.1$ would yield a boundary layer likely too large to be physical, the choice of $\delta$ within reasonable values does not appear to significantly affect the estimates of flux.

The most significant effect on meltwater flux comes from the Brinkman number Br, which defines the rate of shear heating and partially sets the thickness of the temperate zone. This is likely because altering $\mathrm{Br}$ alters the rate of heating and the extent of the temperate ice zone. As the Brinkman number increases from $\sim 5-30$, the meltwater flux increases from $\sim-2$ to $\sim-18$. This difference is approximately an order of magnitude larger than comparable increases in the other parameters, suggesting that constraining the Brinkman number (which depends upon ice thickness, strain rate, and stress) is critical to estimating meltwater flux out of shear margins.

\section{ESTIMATES OF BASAL FLUX IN ANTARCTIC ICE STREAMS}

We apply the model for effective pressure, porosity, and meltwater flux to find estimates of meltwater production in temperate zones of shear margins in Antarctic glaciers. The model takes as an input strain rate, which here is computed from Landsat-8 velocity fields (Gardner and others, 2018), ice thickness, which here is found from BedMachine v01 (Morlighem and others, 2020), and surface mass balance, which here is found from RACMO estimates (Van Wessem and others, 2014). We assume that $\kappa=0.52, \alpha=2.33$, and $\delta=0.001$. We take $\delta$ such that $\delta^{\frac{1}{2}}$ is a small, physically plausible value for the nondimensional height of the boundary layer. Changing the value of $\delta$ would shift the height of the boundary layer (and thus the height at which the inner solution is valid). The parameters used in this section are described in full in Table 1.

To find the basal boundary condition for effective pressure, $N_{0}$, we assume that the till that the ice slides over can be approximated as a perfectly plastic material, an assumption supported by laboratory experiments (Kamb, 1991; Iverson and others, 1998; Tulaczyk and others, 2000a,b) and inferences from 
Table 1. Model parameters for estimates of meltwater flux in all sections except the comparison to numerics.

\begin{tabular}{cccc}
\hline \hline Parameter & Value & Unit & Reason \\
\hline$\kappa$ & 0.52 & & As in Schoof and Hewitt (2016) \\
$\delta$ & 2.33 & & The boundary layer is $\sim 3 \%$ of the ice thickness, a region close to the bed \\
$\epsilon$ & 0.001 & & As in Schoof and Hewitt (2016) \\
$K$ & 0.01 & & \\
$\rho_{w}$ & 2.1 & $\mathrm{~W} \mathrm{~m}^{-1} \mathrm{~K}^{-1}$ & \\
$\rho_{I}$ & 917 & $\mathrm{~kg} \mathrm{~m}^{-3}$ & As in Schoof and Hewitt (2016); Hewitt and Schoof (2017) \\
$\mathcal{L}$ & $3.34 \times 10^{5}$ & $\mathrm{~J} \mathrm{~kg}^{-1}$ & The commonly used value for the stress exponent (Cuffey and Paterson, 2010) \\
$n$ & 3 & $\mathrm{~kg}^{-3} \mathrm{~s}^{-1}$ & The tabulated value for temperate ice (Cuffey and Paterson, 2010) \\
$A$ & $2.4 \times 10^{-24}$ & $\mathrm{~Pa}^{-3}$ & \\
$T_{m}$ & 273 & $\mathrm{~K}^{2}$ & \\
\hline
\end{tabular}

observations (Gillet-Chaulet and others, 2016; Joughin and others, 2019), such that the yield stress $\tau_{*}=$ $c_{0}+\mu N$, where $c_{0}$ is the cohesion of the material and $\mu$ is the internal friction coefficient. Laboratory studies have found $c_{0} \approx 0$ and $\mu \approx \frac{1}{2}$ (Tulaczyk and others, 2000b; Iverson, 2010), meaning the yield stress $\tau_{*}=\frac{1}{2} N$. Assuming that the basal sediments are yielding, a reasonable assumption for the ice flowing at the speeds that West Antarctic ice streams do (Kamb, 1991; Iverson and Iverson, 2001), then $\tau_{*}=\tau_{b}=\frac{1}{2} N$, where $\tau_{b}$ is the basal shear stress. Estimates of basal shear stress have been found in Antarctic ice streams from inverse methods and show $\tau_{b} \leqslant 10 \mathrm{kPa}$ in many regions (MacAyeal, 1992; MacAyeal and others, 1995; Ranganathan and others, 2021a). Therefore, here we define $N_{0}=20 \mathrm{kPa}$.

Figure 3 presents estimates of the thickness of the temperate zone and meltwater flux at the bed for dynamically-significant regions of Antarctica. Dimensional estimates of flux are calculated from nondimensional estimates produced by Equations (21a), (21b), and (22) through the scalings presented in Equation (8). In Equation (22), values of flux are in $\mathrm{m} \mathrm{yr}^{-1}$. To find flux estimates in $\mathrm{m}^{3} \mathrm{yr}^{-1}$, we multiply estimates
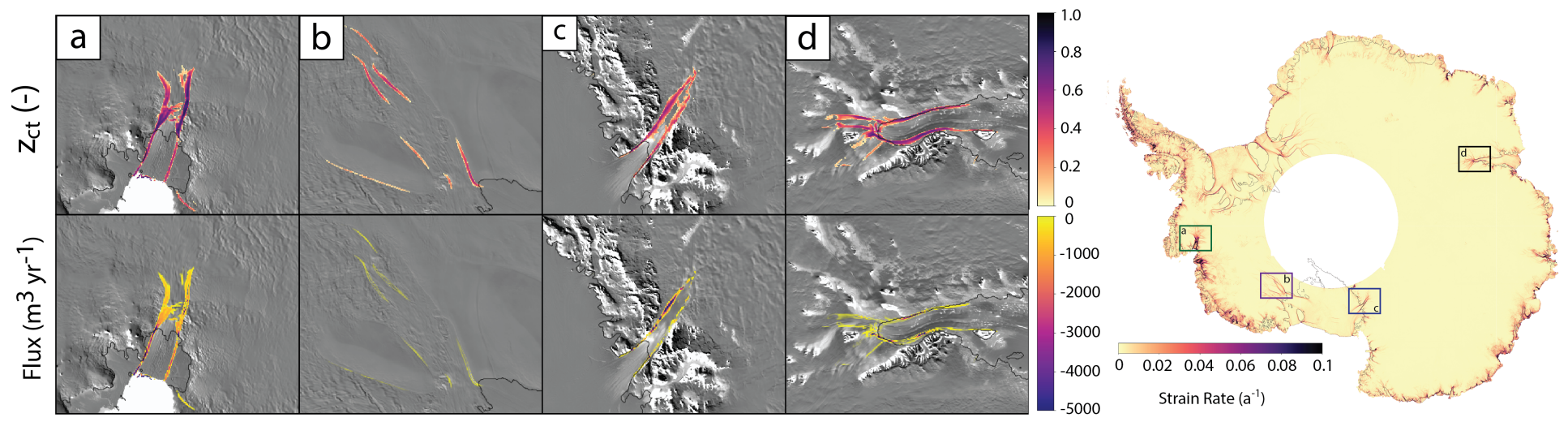

Fig. 3. Thickness of temperate zones and meltwater flux over (a) Pine Island Glacier, (b) Bindschadler Ice Stream, (c) Byrd Glacier, (d) Amery Ice Shelf, computed from observed strain-rates (right). Basal boundary condition is set as $N_{0}=20 \mathrm{kPa}$, as described in text. Colored boxes on observed strain-rates correspond to those in Figure 4. 
by an areal scale. In this case, we use the resolution of strain rate observations (240 m x $240 \mathrm{~m})$.

Regions of high strain rate generally translate to regions with larger temperate zones and thus larger flux of meltwater to the bed. The temperate zone in Pine Island Glacier (Figure 3a) reaches $\sim 75 \%$ of the ice thickness in the fastest-deforming regions, resulting in a meltwater flux of $>2000 \mathrm{~m}^{3} \mathrm{yr}^{-1}$ in that region. However, shallower temperate zones result in very little meltwater flux, such as the situation over the ice shelf on Pine Island Glacier and along the shear margin of Bindschadler Ice Stream (Figure 3b), where the flux is $<1000 \mathrm{~m}^{3} \mathrm{yr}^{-1}$ near the grounding line of the southern shear margin. Due to higher rates of deformation in the margins, there are larger temperate zones and higher meltwater fluxes in Byrd Glacier (Figure 3c) and along the Amery Ice Shelf (Figure 3d).

We estimate full depth profiles of effective pressure $N$, porosity $\phi$, and meltwater flux along three Antarctic shear margins: Pine Island Glacier (Figure 4a), Bindschadler Ice Stream (Figure 4b), and Byrd Glacier (Figure 4c). All three shear margins contain temperate zones. In Bindschadler Ice Stream, this temperate zone is concentrated near the grounding line due to an increase in strain rate driving shear heating (Gardner and others, 2018; Meyer and Minchew, 2018). In Byrd Glacier, there is a region of zero temperate zone thickness in the middle of the transect, likely due to the mountainous topography of the region reducing strain rate or tributaries carrying cold ice into the margin. Pine Island Glacier has a temperate zone for most of the transect, out to $\sim 80 \mathrm{~km}$ upstream of the grounding line, due to its fast flow.

In all three shear margins, effective pressure remains low in the middle of the temperate zone $(\sim 1-4$ $\mathrm{kPa}$ ) and increases rapidly at deeper depths, reaching $N_{0}=20 \mathrm{kPa}$ at the bed. Porosity is high in both Pine Island Glacier and Byrd Glacier where there are large strain rates and thus more significant rates of shear heating $(\sim 4 \%)$, while porosity is lower in Bindschadler Ice Stream $(\sim 1 \%)$. This translates into a reduced meltwater flux out of Bindschadler Ice Stream $\left(\sim 600 \mathrm{~m}^{3} \mathrm{yr}^{-1}\right)$ as compared to Pine Island Glacier $\left(\sim 2000-6000 \mathrm{~m}^{3} \mathrm{yr}^{-1}\right)$ and Byrd Glacier $\left(\sim 6000-10000 \mathrm{~m}^{3} \mathrm{yr}^{-1}\right)$, since increased porosity allows for more drainage of water through the ice column. Therefore, regions of higher porosity translate to increased meltwater flux reaching the bed.

On Pine Island Glacier, there is a reduced meltwater flux at the bed due to a region of reduced porosity, which when combined with the large effective pressure at the bed translates to a near-zero meltwater flux. While the rates of shear heating may be larger in Pine Island Glacier, due to larger strain rates, the flux of meltwater is also dependent upon ice thickness. Since Byrd Glacier has, on average, thinner ice than Pine Island Glacier, this translates into an increased meltwater flux.

Further, there is a region of increased porosity near the bed in Bindschadler Ice Stream $\sim 5-10 \mathrm{~km}$ from the grounding line, which correlates with a region of acceleration seen in Landsat-8 velocity fields. Previous work has suggested that this region of acceleration may be due to changes in effective pressure at the bed due to subglacial hydrologic channels (Meyer and others, 2018) and therefore the estimates provided here may provide a link to estimating the effect of meltwater flux from shear margins on glacial acceleration. Furthermore, using more accurate, spatially varying basal boundary conditions for effective pressure may enable an estimate of the flux into those hydrologic channels that may be affecting the rate of ice flow.

\section{DISCUSSION}

\section{Contributions of Shear Margins to Meltwater at the Bed}

These results demonstrate the potentially significant contribution of shear heating in rapidly deforming ice to meltwater gathering in basal channels and cavities. Other potential sources of meltwater at the bed include melting by geothermal heat flux and melting by friction at the ice-bed interface that is generated due to ice sliding over the basal surface (Tulaczyk and others, 2000b; Fisher and others, 2015). In some regions, surface melt may also be an important source, though we neglect it given cold surface temperatures in 
(a) Pine Island Glacier

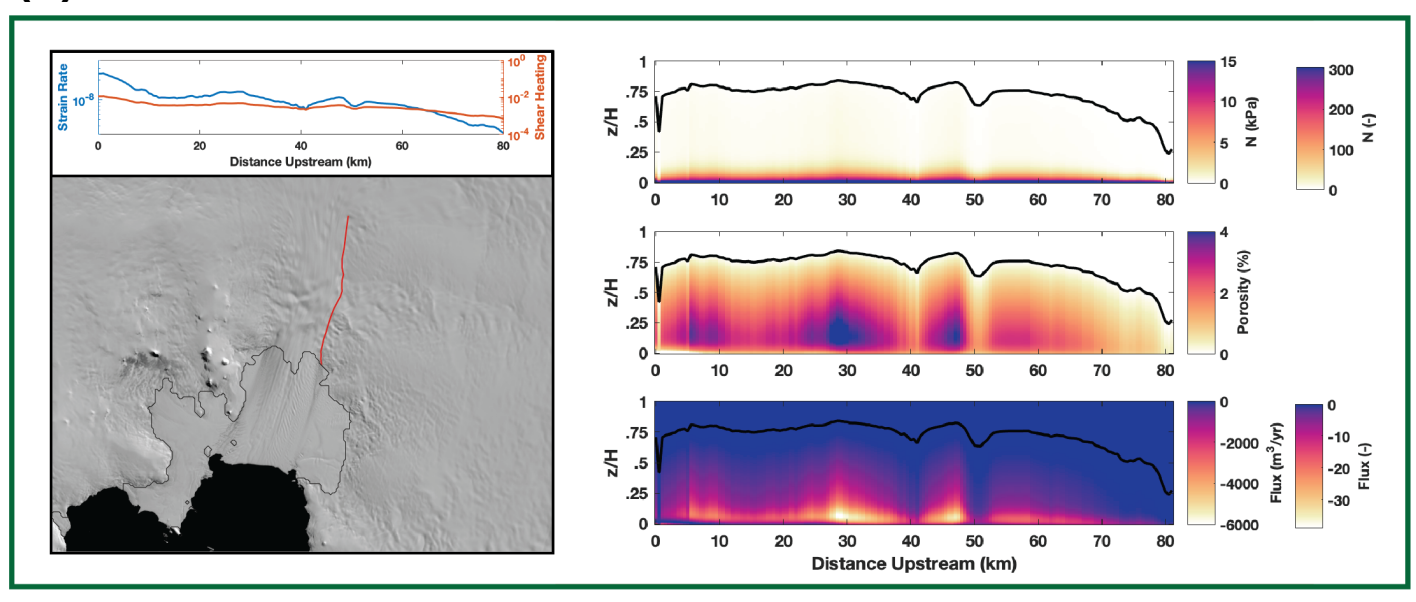

\section{(b) Bindschadler Ice Stream}

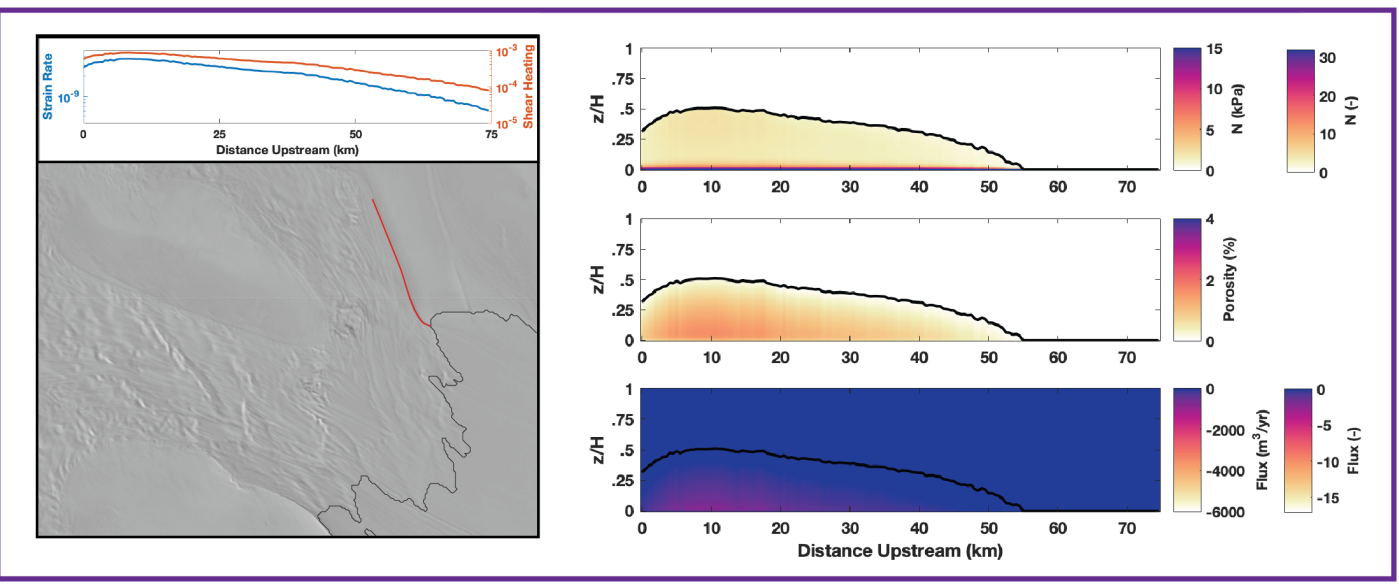

\section{(c) Byrd Glacier}
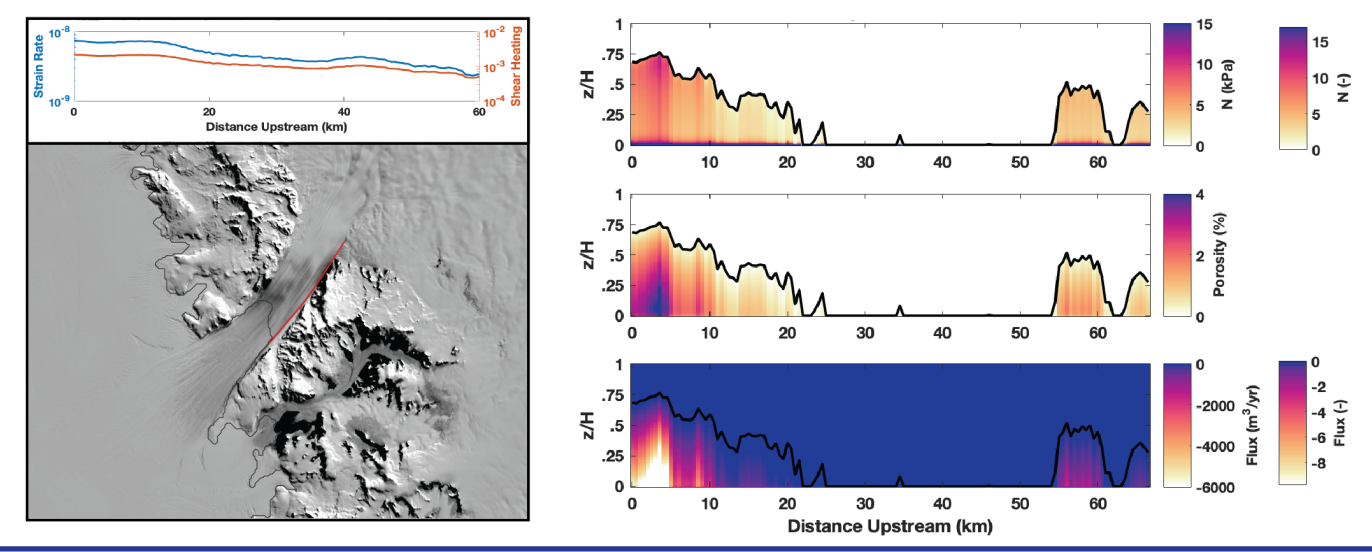

Fig. 4. Profiles of effective pressure, porosity, and meltwater flux along (a) Bindschadler Ice Stream southern margin, (b) Byrd Glacier northern margin, (c) Pine Island Glacier southern margin. Colors of boxes around figures correspond to those in Figur e 3. MODIS satellite imagery shown on the first row, with profiles of strain rates with distance upstream as an inset and the red line denoting the locations of the transects corresponding to the profiles shown on the second row. Second colorbar denotes nondimensional estimates. 

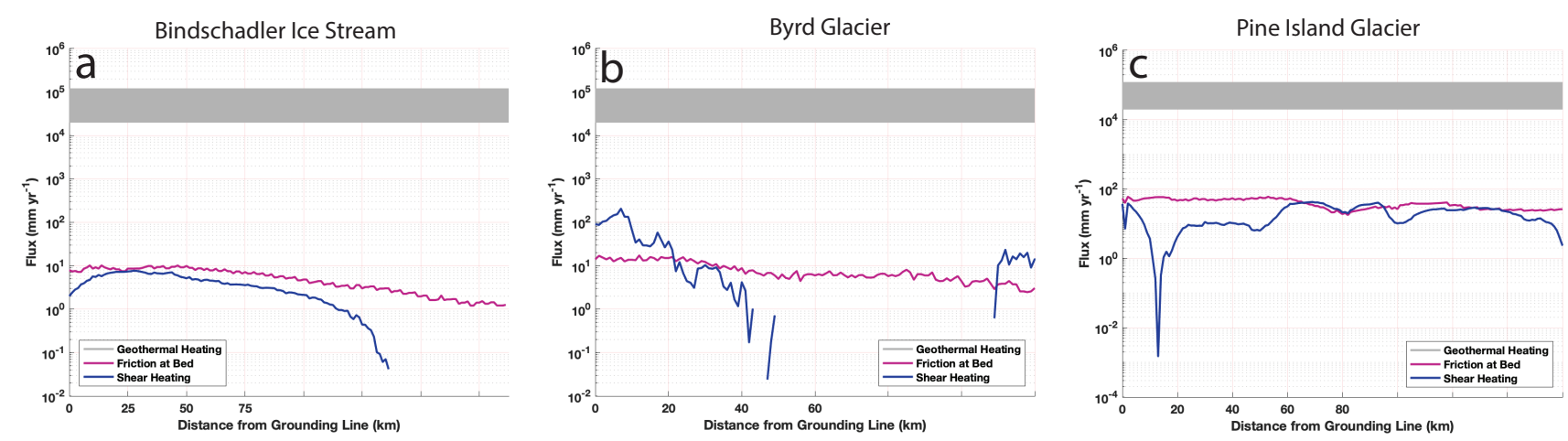

Fig. 5. Contributions to meltwater flux into subglacial hydrologic channels from geothermal heating, frictional heating at the bed, and shear heating in (a) Bindschadler Ice Stream, (b) Byrd Glacier, (c) Pine Island Glacier.

Antarctica. The contributions from geothermal heat flux and frictional melting at the bed were modeled by Robel and others (2013), incorporating melting by geothermal heat flux, sliding at the bed, and conduction into the ice. Here, we neglect the effect of thermal conduction into the ice as there is no conduction into a temperate ice zone due to the constant temperature. We apply the same model to estimate the comparative contributions of geothermal heat and sliding at the bed to our new estimates of melting by shear heating in margins. Following Robel and others (2013), we define the meltwater supply at the bed $s$ as

$$
s=\frac{1}{\rho_{i} \mathcal{L}}\left[G+\tau_{b} u_{b}\right]+J
$$

where $\rho_{i}$ is ice density, $\mathcal{L}$ is the latent heat of fusion, $G$ is the geothermal heat flux, $\tau_{b}$ is basal shear stress, and $u_{b}$ is basal velocity. $J$ is the (dimensional) flux magnitude, computed from Equation (22). To find melting by sliding at the bed, we assume that vertical shearing is negligible such that $u_{s} \approx u_{b}$, where $u_{s}$ is surface velocity. This is a reasonable assumption in most West Antarctic ice streams, where the ice slips over weak till and sediments (Joughin and others, 2004; Morlighem and others, 2013; Ranganathan and others, 2021a). This assumption provides an upper bound on melt rate from frictional heating. So, we can find basal shear stress from effective pressure as described in the previous section.

To estimate melting by geothermal heat flux, we take values of geothermal heat flux inferred from observational and field studies (Schroeder and others, 2014; Fisher and others, 2015). Schroeder and others (2014) estimated geothermal heat flux underneath Thwaites Glacier, another glacier in West Antarctica, using radar and found $G \approx 114 \mathrm{~mW} \mathrm{~m}^{-2}$. Fisher and others (2015) presented estimates of geothermal heat flux from geomagnetic data and borehole measurements and found that flux ranges from $\approx 60-100 \mathrm{~mW}$ $\mathrm{m}^{-2}$ in West Antarctica. However, there is still significant uncertainty in estimates of geothermal heat flux (Burton-Johnson and others, 2020). Therefore, we compute a range of meltwater flux from geothermal heating, assuming that geothermal heat flux falls between $20-120 \mathrm{~mW} \mathrm{~m}^{-2}$. These values encompass most of the estimates of geothermal heat flux in non-volcanic regions of Earth (Turcotte and Schubert, 2002).

The contributions of geothermal heating, frictional heating from sliding at the bed, and shear heating (estimated in this study) to meltwater flux are presented in Figure 5. Contributions from geothermal heat flux are orders of magnitude larger than the other sources $\left(\sim 10^{4}-10^{5} \mathrm{~mm} \mathrm{yr}^{-1}\right.$, depending on the magnitude of geothermal heat flux) due to the high rates of heat flux. However, the estimate of meltwater production from geothermal heat flux provided here assumes a dry bed. In reality, there is liquid water at the bed which reduces geothermal heat flux due to the high heat capacity of water and movement of water through active hydrological systems. Therefore, these estimates are an upper bound 
for melting by geothermal heat flux and it may be true that the meltwater production from this process is much lower. Frictional heating at the bed and shear heating both contribute $\sim 1-10^{2} \mathrm{~mm} \mathrm{yr}^{-1}$ and the meltwater contributions from these two sources are approximately the same order of magnitude in all three glaciers. Further, we are again not accounting for feedbacks between these processes and water content. Lubrication at the bed by liquid water may reduce frictional heating and thus reduce the contribution of frictional heating to meltwater production at the bed.

In Bindschadler Ice Stream, the shear heating contribution reaches approximately the contribution of frictional heating at the bed at the region of highest flux (and highest strain rate). In Byrd Glacier, shear heating at the bed contributes more meltwater to subglacial channels than frictional heating at the bed does, though the shear heating contribution decreases with distance upstream. Very far upstream $(\sim 80$ $\mathrm{km}$ ), there is a region of high meltwater flux contribution from shear heating. In Pine Island Glacier, the contribution of shear heating is approximately the same as the contribution of frictional heating at the bed until near the grounding line, where meltwater flux decreases $\sim 3$ orders of magnitude. This decrease can be seen in estimates of porosity (Figure 4c), where there is a narrow band of reduced porosity near the grounding line. This may be due to an anomaly in ice thickness or in the nonlinear equation solver that finds the outer solution of porosity from Equation (12). The resolution of the data $(250 \mathrm{~m} \times 250 \mathrm{~m})$ is not fine enough to determine whether this reduction has a clear physical basis. Along the rest of the shear margin, the contributions of shear heating and frictional heating at the bed are approximately of the same magnitude. In regions where surface melting is significant (such as in the Greenland Ice Sheet), the contribution from surface melt would likely be dominant over the three sources presented here, though on the Antarctic Ice Sheet that contribution is likely small.

These results suggest that shear heating is a non-negligible contribution of meltwater to subglacial channels. This would imply that explicitly modeling polythermal ice, accounting for boundary layers, is necessary to gain an accurate estimate of the water content in subglacial channels. Furthermore, these results support previous work that propose feedbacks between rapidly-deforming ice and subglacial hydrology. Many studies have suggested that melting from shear margins drains to the bed and provides a control on the width and position of ice streams, particularly in ice streams that are not topographically controlled (Jacobson and Raymond, 1998; Perol and Rice, 2015; Perol and others, 2015; Meyer and others, 2018). Further, studies have proposed that water content in subglacial till and in subglacial channels can affect the rate of ice flow over the bed by affecting the strength of subglacial till and thus the rate of basal sliding (Perol and Rice, 2015; Elsworth and Suckale, 2016; Damsgaard and others, 2016; Meyer and others, 2016, 2018; Haseloff and others, 2019). These results also suggest that shear heating must be accounted for as a contribution to subglacial lakes and may be a way to more accurately model the volume of water in subglacial lakes. Accurate estimates and modeling of the contribution of water to subglacial lakes may be a step towards predicting changes to flow speed due to floods from subglacial lakes (Stearns and others, 2008; Siegfried and others, 2016; Stubblefield and others, 2021). Finally, the localization of meltwater delivery in shear margins has important implications for the spatial variability of basal shear stress and the patterns of subglacial channels underneath Antarctic ice streams. Our estimates may provide a step towards illuminating the processes affecting basal properties, shear margin migration, and freshwater input into the ocean. Further, these results can provide an input into subglacial routing models which may estimate where water drained from temperate ice flows and how much ends up in subglacial lakes. We reserve for future work an exploration of where the meltwater goes.

\section{Summary of Key Assumptions and Future Work}

This study makes a few assumptions that impact these results, though we expect the main conclusions to hold. In particular, we assume a constant ice softness parameter $A$ and take a simple, isotropic form of Glen's law that computes ice viscosity based solely on stress and strain rate. However, factors such as anisotropy (fabric), ice temperature, and ice porosity likely affect ice viscosity. Incorporating the effect of 
anisotropy, ice temperature and ice porosity in ice softness will likely increase the incidence of temperate zones and increase meltwater flux from temperate ice in shear margins. Currently, anisotropy is parameterized through fabric enhancement factors in the flow law, though the values of these enhancement factors are uncertain. Therefore, we keep enhancement factors implicit within the value of $A$ in this study in order to reduce uncertain parameters in the model and we reserve for future work a more complete study of the effect of anisotropy on rates of deformation and, therefore, on the generation of temperate zones. Given that ice in shear margins is approximately in simple shear, many studies suggest that a scalar enhancement to the ice softness parameter $A$ is appropriate for these conditions (Ma and others, 2010; Minchew and others, 2018; Graham and others, 2018). Any enhancement to strain rates not captured in our constant value for $A$ would likely increase ice temperatures from a given strain rate and therefore increase the thickness of existing temperate zones and create temperate zones where we do not estimate any in this study.

Including ice temperature in the ice softness parameter $A$ through an Arrhenius relation has been done in previous studies and these studies have shown that the generation of temperate ice from shear margins is likely (Suckale and others, 2014; Meyer and others, 2018; Haseloff and others, 2019). Incorporating temperature into $A$ may also produce larger and more extensive temperate zones than we present here, because shear heating would soften the ice and enable faster deformation, thereby increasing the Brinkman number $\mathrm{Br}$ and directly increasing the thickness of temperate zones. In the Supplement Figure S4, we show that regions and extent of temperate ice zones estimated are larger when we allow for coupling between $A$ and ice temperature, suggesting larger meltwater fluxes than those presented here.

A similar effect occurs when incorporating ice porosity into ice softness $A$ for regions of temperate ice. The effect of porosity on ice softness is generally parameterized by $A=A_{0}(1+c \phi)$ where $c \approx 200$ (Duval, 1977; Cuffey and Paterson, 2010), and therefore increasing porosity in temperate zones, as seen in this study, would result in an increase in ice softness (Haseloff and others, 2019). Softer ice would deform faster, increasing the rate of shear heating and thus increasing the presence of temperate zones. Given that, in this study, we use a constant ice softness $A$, the estimates presented in this study can be thought of as a lower bound on meltwater flux from shear margins in the absence of horizontal advection, and we reserve for future work a full consideration of the feedbacks involved with porosity, ice temperature, and ice softness.

Here, we compute the rates of shear heating following Meyer and Minchew (2018), which computes the Brinkman number $\mathrm{Br}$ from the rate of work done during deformation $W$. This implicitly assumes that all of the work done during deformation gets dissipated as heat. If we define an energy partitioning parameter $\Theta$ as the fraction of work done during deformation that is dissipated as heat and estimated that in rapidly-deforming regions, values of $\Theta$ may be lower than $\Theta=1$ in ice stream and glacier shear margins. If we apply initial estimates of $\Theta$ to estimating shear heating, the temperate zones in both Pine Island Glacier and Bindschadler Ice Stream may become negligible due to the deformational work driving dynamic recrystallization mechanisms rather than heating (presented fully in the Supplement). Byrd Glacier has a reduced temperate zone and therefore a reduced meltwater flux. We reserve for future work an exploration of the effects of energy partitioning on meltwater flux estimates.

In this study we take an isotropic form of Glen's flow law with the stress exponent $n=3$. While this value is commonly used in glaciological literature and is supported by laboratory experiments (Jezek and others, 1985; Cuffey and Paterson, 2010), recent studies have suggested that in Antarctic conditions, the value of the stress exponent $n$ may be closer to $n=4$ (Millstein and others, 2021; Ranganathan and others, 2021b). Ice rheology affects these results through estimates of ice temperature and therefore estimates of the thickness of temperate zones. Larger values of $n$ allow for higher rates of shear heating and thus would produce more significant temperate zones. This would increase our estimates of meltwater flux to the bed and extend the regions in which considering polythermal glacier structures is necessary. Further, there has been some consideration for the effect of ice temperature and ice deformation rate on the stress exponent $n$. In particular, studies have considered how the stress exponent $n$ changes with liquid water content in the ice and have found significant softening and acceleration due to the presence of liquid water (Barnes 
and others, 1971; Duval, 1977; de La Chapelle and others, 1995) and potential changes in the deformation mechanism, resulting in estimates of $n$ as low as $n=1.1$ for large water contents (De La Chapelle and others, 1999; Adams and others, 2021).

Finally, we neglect the effects of lateral advection of cold ice into shear margins along the length of the shear margin to focus on studying the effect of existing temperate zones on meltwater flux at the bed. These effects have been examined in previous studies, which found that lateral advection reduces ice temperature in the shear margin, which would likely reduce the estimates of meltwater flux seen here (Suckale and others, 2014; Haseloff and others, 2019; Hunter and others, 2021). While in this study we focus on estimating meltwater flux in the absence of lateral advection in order to focus on the physics of melt and transport, these previous studies provide a framework for incorporating lateral advection, such as using a lateral advection parameter that subtracts from the Brinkman number to find the rate of shear heating (Meyer and Minchew, 2018). This is a necessary next step to fully realizing the presence of temperate zones and ice temperature profiles in Antarctica.

\section{CONCLUSION}

In this study we consider the contribution of shear heating in the margins of ice streams to the flux of meltwater to the bed, which often flows in channels that transport water to the ocean and affect the rates of ice flow and the geometry of ice streams. We build upon the polythermal ice flow model developed by Schoof and Hewitt (2016) to estimate effective pressure, porosity, and meltwater flux in regions of temperate ice generated by shear heating. We find analytical estimates for three fields that compare well with numerical model estimates. We then apply this model to Antarctic glaciers to estimate the contribution of meltwater flux from shear margins. We find that shear heating supplies $\sim 1000-2000 \mathrm{~m}^{3} \mathrm{yr}^{-1}$, a rate that is comparable to the contribution from frictional heating at the bed by orders of magnitude smaller than the likely contribution from geothermal heat flux. Further, the meltwater supply from shear margins is highly localized, and previous studies have suggested that the localized increase in water content at the bed may influence yielding of the bed and the location of ice stream margins, which has implications for large-scale ice stream flow (Haseloff and others, 2019).

To construct an analytical model, we made a number of simplifications, the most significant of which are assuming a constant ice softness parameter $A$, neglecting lateral advection, and assuming steady state. A necessary direction of future work is to incorporate the effects of ice temperature, porosity, and anisotropy into ice rheology. This would likely increase the estimates of meltwater flux due to increasing the rate of shear heating in softer ice and increasing the thickness of temperate ice zones, as shown in the Supplement. However, the incorporation of lateral advection may reduce estimates of meltwater flux due to the advection of cold ice into the shear margin. Finally, another important direction for future work is to consider timedependence and the evolution of meltwater flux. The results presented here suggest a need to incorporate models for polythermal ice flow, as done in Schoof and Hewitt (2016) and Hewitt and Schoof (2017), and to constrain ice flow properties in temperate ice. Further, these results provide a framework for considering the feedbacks between rapid, localized deformation and basal properties and the effects of these feedbacks on ice flow. Finally, the estimates presented here may shed light on the amount of meltwater in subglacial channels and subglacial lakes, which is currently uncertain and has the potential impact ice flow significantly.

\section{APPENDIX}

\section{Appendix A: Nondimensionalization}

Let 


$$
\begin{aligned}
& \tilde{\mathcal{H}}=[\mathcal{H}] \mathcal{H} \\
& \tilde{z}=H z \\
& \tilde{T}=[T] T+T_{m} \\
& \tilde{\phi}=[\phi] \phi \\
& \tilde{N}=[N] N \\
& \tilde{t}=[t] t
\end{aligned}
$$

$$
\begin{array}{r}
{[\mathcal{H}]=\rho_{I} c_{p} \Delta T} \\
{[T]=\Delta T} \\
{[\phi]=\epsilon=\frac{\rho_{I} c_{p} \Delta T}{\rho_{w} \mathcal{L}}} \\
{[N]=\frac{\left[\eta_{I}\right] K \Delta T}{\epsilon \rho_{w} \mathcal{L} H^{2}}} \\
{[t]=\frac{H^{2} \rho_{I} c_{p}}{K}}
\end{array}
$$

${ }_{484}$ We non-dimensionalize Equation (7a):

$$
\begin{aligned}
& \frac{[\mathcal{H}]}{[t]} \frac{\partial \mathcal{H}}{\partial t}+a \frac{[\mathcal{H}]}{H} \frac{\partial \mathcal{H}}{\partial z}-K \frac{[T]}{H^{2}} \frac{\partial^{2} T}{\partial z^{2}}=W-\frac{\rho_{w} \mathcal{L}[\phi][N]}{\left[\eta_{I}\right]} \phi N \\
& \Longrightarrow \frac{\partial \mathcal{H}}{\partial t}+a \frac{[t]}{H} \frac{\partial \mathcal{H}}{\partial z}-K \frac{[T][t]}{[\mathcal{H}] H^{2}} \frac{\partial^{2} T}{\partial z^{2}}=W \frac{[t]}{[\mathcal{H}]}-\frac{\rho_{w} \mathcal{L}[t][\phi][N]}{\left[\eta_{I}\right][\mathcal{H}]} \phi N \\
& \Longrightarrow \frac{\partial \mathcal{H}}{\partial t}+\left(\frac{a H^{2} \rho_{I} c_{p}}{H K}\right) \frac{\partial \mathcal{H}}{\partial z}-\left(\frac{K \Delta T H^{2} \rho_{I} c_{p}}{H^{2} K \rho_{I} c_{p} \Delta T}\right) \frac{\partial^{2} T}{\partial z^{2}}=\left(\frac{H^{2} \rho_{I} c_{p}}{K \rho_{I} c_{p} \Delta T}\right) W-\left(\frac{\rho_{w} \mathcal{L} H^{2} \epsilon \eta_{I} K \Delta T}{\eta_{I} K \Delta T \epsilon \rho_{w} \mathcal{L} H^{2}}\right) \phi N \\
& \Longrightarrow \frac{\partial \mathcal{H}}{\partial t}+\left(\frac{a H \rho_{I} c_{p}}{K}\right) \frac{\partial \mathcal{H}}{\partial z}-\frac{\partial^{2} T}{\partial z^{2}}=\left(\frac{H^{2}}{K \Delta T}\right) W-\phi N
\end{aligned}
$$

$$
\begin{aligned}
\mathrm{Br} & =\frac{W H^{2}}{K \Delta T} \\
\mathrm{Pe} & =\frac{a H \rho_{I} c_{p}}{K}
\end{aligned}
$$

486 So we can rewrite Equation (28) in terms of these numbers:

$$
\frac{\partial \mathcal{H}}{\partial t}+\operatorname{Pe} \frac{\partial \mathcal{H}}{\partial z}-\frac{\partial^{2} T}{\partial z^{2}}=\mathrm{Br}-\phi N
$$

487 Now we non-dimensionalize Equation (7b):

$$
\begin{aligned}
& \frac{1}{H} \frac{\partial}{\partial z}\left\{\frac{k_{0}([\phi] \phi)^{\alpha}}{\eta_{w}}\left[-\left(\rho_{w}-\rho_{I}\right) g+\frac{[N]}{H} \frac{\partial N}{\partial z}\right]\right\}=\frac{[\phi][N]}{\eta_{I}} \phi N \\
& \Longrightarrow \frac{k_{0} \epsilon^{\alpha}}{H \eta_{w}} \frac{\partial}{\partial z}\left\{\phi^{\alpha}\left[-\left(\rho_{w}-\rho_{I}\right) g+\frac{[N]}{H} \frac{\partial N}{\partial z}\right]\right\}=\frac{\epsilon[N]}{\eta_{I}} \phi N \\
& \Longrightarrow \frac{k_{0} \epsilon^{\alpha}\left(\rho_{w}-\rho_{I}\right) g}{H \eta_{w}} \frac{\partial}{\partial z}\left\{\phi^{\alpha}\left[-1+\frac{[N]}{H\left(\rho_{w}-\rho_{I}\right) g} \frac{\partial N}{\partial z}\right]\right\}=\frac{\epsilon[N]}{\eta_{I}} \phi N
\end{aligned}
$$


488

$$
\begin{aligned}
\phi_{1}(\hat{z}) & =\int \frac{\mathrm{Br}-\phi_{0} N_{\text {inner }}}{\mathrm{Pe}} d \hat{z} \\
& =\int \frac{\mathrm{Br}}{\mathrm{Pe}}-\frac{\phi_{0}}{\mathrm{Pe}}\left[N_{\text {outer }}(0)+\left[N_{0}-N_{\text {outer }}(0)\right] \exp [-\sqrt{a} \hat{z}]\right] d \hat{z} \\
& =\int \frac{\mathrm{Br}-\phi_{0} N_{\text {outer }}(0)}{\mathrm{Pe}}-\frac{\phi_{0}}{\mathrm{Pe}}\left[N_{0}-N_{\text {outer }}(0)\right] \exp [-\sqrt{a} \hat{z}] d \hat{z} \\
& =\left[\frac{\mathrm{Br}-\phi_{0} N_{\text {outer }}(0)}{\mathrm{Pe}}\right] \hat{z}+\frac{\phi_{0}}{\sqrt{a} \mathrm{Pe}}\left[N_{0}-N_{\text {outer }}(0)\right] \exp [-\sqrt{a} \hat{z}]+C
\end{aligned}
$$

To find $C$, we use the higher-order matching condition 


$$
\lim _{z \rightarrow \infty} \delta^{\beta} \phi_{1}(\hat{z})=\lim _{z \rightarrow 0} \phi_{\text {outer }}(z)
$$

501 So we have have

$$
y=y_{0}+\frac{z}{z_{c t}} y_{1}
$$

We can expand Equation (12) as

$$
\operatorname{Pe}\left(y_{0}+\frac{z}{z_{c t}} y_{1}\right)-\kappa\left(y_{0}+\frac{z}{z_{c t}} y_{1}\right)^{\alpha}=\operatorname{Br}\left(z-z_{c t}\right)
$$

At zeroth order, we have $\operatorname{Pe} y_{0}-\kappa y_{0}^{\alpha}=\operatorname{Br}\left(z-z_{c t}\right)$, in which $y_{0}=\phi_{\text {outer }}(0)$. At first order $\left(\mathcal{O}\left(\frac{z}{z_{c t}}\right)\right)$, we

$$
\begin{gathered}
\mathrm{Pe} y_{1}-\kappa \alpha y_{0}^{\alpha-1} y_{1}=\operatorname{Br} z_{c t} \\
\Longrightarrow y_{1}=-\frac{\operatorname{Br} z_{c t}}{\kappa \alpha y_{0}^{\alpha-1}-\mathrm{Pe}}
\end{gathered}
$$

502 Now let's expand $\phi_{1}(\hat{z})$ for large $\hat{z}$. We note that $\hat{z}=\frac{z}{\delta^{\beta}}$ and we do a change of variables:

$$
\begin{aligned}
\lim _{z \rightarrow \infty} \int \delta^{\beta} \frac{\partial \phi_{1}}{\partial \hat{z}} d \hat{z} & =\delta^{\beta}\left[\frac{\mathrm{Br}-\phi_{0} N_{\text {outer }}(0)}{\delta^{\beta} \mathrm{Pe}}\right] \hat{z}+\lim _{z \rightarrow \infty} \delta^{\beta} \frac{\phi_{0}}{\sqrt{a} \mathrm{Pe}}\left[N_{0}-N_{\text {outer }}(0)\right] \exp \left[-\frac{\sqrt{a}}{\delta^{\beta}} z\right]+C \\
& =\left[\frac{\operatorname{Br}-\phi_{0} N_{\text {outer }}(0)}{\mathrm{Pe}}\right] \hat{z}+C
\end{aligned}
$$

Here we employ higher-order matching since we're interested in the constant of integration for $\phi_{1}$. In this case, the higher-order matching condition is $\lim _{z \rightarrow \infty} \delta^{\beta} \phi_{1}(z)=\frac{z}{z_{c t}} y_{1}$. So the matching condition from Equation (48) is

$$
\begin{gathered}
{\left[\frac{\mathrm{Br}-\phi_{0} N_{\text {outer }}(0)}{\mathrm{Pe}}\right] z+C=-\frac{z}{z_{c t}} \frac{\mathrm{Br} z_{c t}}{\kappa \alpha y_{0}^{\alpha-1}-\mathrm{Pe}}} \\
\Longrightarrow\left[\frac{\mathrm{Br}-\phi_{0} N_{\text {outer }}(0)}{\mathrm{Pe}}\right]+C=-\frac{\mathrm{Br}}{\kappa \alpha y_{0}^{\alpha-1}-\mathrm{Pe}}
\end{gathered}
$$

506 Recall that $N_{\text {outer }}(0)=-\frac{\operatorname{Br} \kappa \alpha \phi_{0}^{\alpha-2}}{\operatorname{Pe}-\kappa \alpha \phi_{0}^{\alpha-1}}$. We plug this into Equation (57) such that 


$$
\begin{aligned}
& {\left[\frac{\mathrm{Br}-\phi_{0}-\frac{\mathrm{Br} \kappa \alpha \phi_{0}^{\alpha-2}}{\mathrm{Pe}-\kappa \alpha \phi_{0}^{\alpha-1}}}{\mathrm{Pe}}\right]+C=-\frac{\mathrm{Br}}{\kappa \alpha y_{0}^{\alpha-1}-\mathrm{Pe}}} \\
& \Longrightarrow \frac{\mathrm{Br}}{\mathrm{Pe}}-\frac{\phi_{0}}{\mathrm{Pe}}\left[-\frac{\mathrm{Br} \kappa \alpha \phi_{0}^{\alpha-2}}{\mathrm{Pe}-\kappa \alpha \phi_{0}^{\alpha-1}}\right]+C=-\frac{\mathrm{Br}}{\kappa \alpha \phi_{0}^{\alpha-1}-\mathrm{Pe}} \\
& \Longrightarrow \frac{\mathrm{Br}}{\mathrm{Pe}}-\frac{1}{\mathrm{Pe}}\left[-\frac{\mathrm{Br} \kappa \alpha \phi_{0}^{\alpha-1}}{\mathrm{Pe}-\kappa \alpha \phi_{0}^{\alpha-1}}\right]+C=-\frac{\mathrm{Br}}{\kappa \alpha \phi_{0}^{\alpha-1}-\mathrm{Pe}} \\
& \Longrightarrow \frac{\mathrm{Br}\left[\mathrm{Pe}-\kappa \alpha \phi_{0}^{\alpha-1}\right]+\mathrm{Br} \kappa \alpha \phi_{0}^{\alpha-1}}{\mathrm{Pe}\left[\mathrm{Pe}-\kappa \alpha \phi_{0}^{\alpha-1}\right]}+C=-\frac{\mathrm{Br}}{\kappa \alpha \phi_{0}^{\alpha-1}-\mathrm{Pe}} \\
& \Longrightarrow \frac{\mathrm{Br}}{\mathrm{Pe}-\kappa \alpha \phi_{0}^{\alpha-1}}+C=-\frac{\mathrm{Br}}{\kappa \alpha \phi_{0}^{\alpha-1}-\mathrm{Pe}} \\
& \Longrightarrow C=0
\end{aligned}
$$

507

508

We then plug this $C$ into Equation (47) to finalize our equation for the first-order solution of porosity:

$$
\phi_{1}(\hat{z})=\left[\frac{\mathrm{Br}-\phi_{0} N_{\text {outer }}(0)}{\mathrm{Pe}}\right] \hat{z}+\frac{\phi_{0}}{\sqrt{a} \mathrm{Pe}}\left[N_{0}-N_{\text {outer }}(0)\right] \exp [-\sqrt{a} \hat{z}]
$$

We can plug this into $\phi_{\text {inner }}(\hat{z})=\phi_{0}(\hat{z})+\delta^{\frac{1}{2}} \phi_{1}(\hat{z})$ to arrive at our inner solution for porosity:

$$
\phi_{\text {inner }}=\phi_{\text {outer }}(0)+\delta^{\frac{1}{2}}\left[\left[\frac{\mathrm{Br}-\phi_{0} N_{\text {outer }}(0)}{\mathrm{Pe}}\right] \hat{z}+\frac{\phi_{0}}{\sqrt{a} \mathrm{Pe}}\left[N_{0}-N_{\text {outer }}(0)\right] \exp [-\sqrt{a} \hat{z}]\right]
$$

\section{APPENDIX C: FINDING COMPOSITE SOLUTIONS}

To find the composite solution for effective pressure, we consider the overlap region

$$
\lim _{\hat{z} \rightarrow \infty} N_{\text {inner }}(\hat{z})=\lim _{\tilde{z} \rightarrow 0} N_{\text {outer }}(\tilde{z})=N_{\text {outer }}(0)
$$

1 So the composite solution for effective pressure is

$$
N_{\text {composite }}=N_{\text {outer }}+\left(N_{0}-N_{\text {outer }}(0)\right) \exp (-\sqrt{a} \hat{z})
$$

2 To find the composite solution for porosity, we consider the overlap region

$$
\lim _{\hat{z} \rightarrow \infty} \phi_{\text {inner }}(\hat{z})=\lim _{z \rightarrow 0} \phi_{\text {outer }}(z)
$$

Recall from Equation (49) that we can expand the outer solution for small $z$. We take the expansion as the matching condition such that 


$$
\lim _{\hat{z} \rightarrow \infty} \phi_{\text {inner }}(\hat{z})=\lim _{z \rightarrow 0} \phi_{\text {outer }}(z)=\phi_{\text {outer }}(0)+\frac{z}{z_{c t}}\left[-\frac{\mathrm{Br} z_{c t}}{\kappa \alpha \phi_{0}^{\alpha-1}-\mathrm{Pe}}\right]
$$

Therefore the composite solution of porosity combines Equations 12 and 65 and can be written as

$$
\phi_{\text {composite }}=\phi_{\text {outer }}+\phi_{\text {inner }}-\left[\phi_{\text {outer }}(0)+\frac{z}{z_{c t}}\left[-\frac{\mathrm{Br} z_{c t}}{\kappa \alpha \phi_{0}^{\alpha-1}-\mathrm{Pe}}\right]\right]
$$

\section{ACKNOWLEDGEMENTS}

M.I.R. was supported by the Martin Fellowship and from NSFGEO-NERC award 1853918. B.M. acknowledges funding from NSFGEO-NERC award 1853918, NSF-NERC award 1739031, and NEC Corporation Fund for Research in Computers and Communications. CRM was supported by NSF?2012958.

\section{DATA STATEMENT}

The source code for the model presented in this study, along with the data needed to generate Figure 4, are openly available at https://github.com/megr090/MeltwaterFlux. No new data were produced for this study, and data used in this study are publicly available through their respective publications.

\section{REFERENCES}

Adams CJC, Iverson NR, Helanow C, Zoet LK and Bate CE (2021) Softening of Temperate Ice by Interstitial Water. Frontiers in Earth Science, 9(July), 1-11, ISSN 2296-6463 (doi: 10.3389/feart.2021.702761)

Alley KE, Scambos TA, Siegfried MR and Fricker HA (2016) Impacts of warm water on Antarctic ice shelf stability through basal channel formation. Nature Geoscience, 9(4), 290-293, ISSN 17520908 (doi: 10.1038/ngeo2675)

Barnes P, Tabor D and Walker JCF (1971) The friction and creep of polycrystalline ice. Proceedings of the Royal Society of London. A. Mathematical and Physical Sciences, 324(1557), 127-155, ISSN 2053-9169 (doi: 10.1098/ rspa.1971.0132)

Bender C and Orszag S (1999) Advanced Mathematical Methods for Scientists and Engineers: Asymptotic Methods and Perturbation Theory. Springer, ISBN 0387989315

Burton-Johnson A, Dziadek R and Martin C (2020) Geothermal heat flow in Antarctica: current and future directions. The Cryosphere Discussions, 1-45, ISSN 1994-0416 (doi: 10.5194/tc-2020-59)

Cuffey K and Paterson W (2010) The Physics of Glaciers. Elsevier, fourth edition

Damsgaard A, Egholm DL, Beem LH, Tulaczyk S, Larsen NK, Piotrowski JA and Siegfried MR (2016) Ice flow dynamics forced by water pressure variations in subglacial granular beds. Geophysical Research Letters, 43(23), 12,165-12,173, ISSN 19448007 (doi: 10.1002/2016GL071579)

Dash JG, Rempel AW and Wettlaufer JS (2006) The physics of premelted ice and its geophysical consequences. Reviews of Modern Physics, 78(3), 695-741, ISSN 15390756 (doi: 10.1103/RevModPhys.78.695)

de La Chapelle S, Duval P and Baudelet B (1995) Compressive creep of polycrystalline ice containing a liquid phase. Scripta Metallurgica et Materialia, 33(3), 447-450, ISSN 0956716X (doi: 10.1016/0956-716X(95)00207-C) 
De La Chapelle S, Milsch H, Castelnau O and Duval P (1999) Compressive creep of ice containing a liquid intergranular phase: Rate-controlling processes in the dislocation creep regime. Geophysical Research Letters, 26(2), 251-254, ISSN 00948276 (doi: 10.1029/1998GL900289)

De Rydt J, Reese R, Paolo FS and Gudmundsson GH (2021) Drivers of Pine Island Glacier speed-up between 1996 and 2016. The Cryosphere, 15(1), 113-132, ISSN 1994-0424 (doi: 10.5194/tc-15-113-2021)

Duval P (1977) The role of the water content on the creep rate of polycrystalline ice. IAHS Publ., 118, 29-3332

Elsworth CW and Suckale J (2016) Rapid ice flow rearrangement induced by subglacial drainage in West Antarctica. Geophysical Research Letters, 43(22), 11,697-11,707, ISSN 0094-8276 (doi: 10.1002/2016GL070430)

Engelhardt H and Kamb B (1997) Basal hydraulic system of a West Antarctic ice stream: constraints from borehole observations. Journal of Glaciology, 43(144), 207-230, ISSN 0022-1430 (doi: 10.3189/S0022143000003166)

Fisher AT, Mankoff KD, Tulaczyk SM, Tyler SW and Foley N (2015) High geothermal heat flux measured below the West Antarctic Ice Sheet. Science Advances, 1(6), ISSN 23752548 (doi: 10.1126/sciadv.1500093)

Fricker HA, Scambos T, Bindschadler R and Padman L (2007) An active subglacial water system in West Antarctica mapped from space. Science, 315(5818), 1544-1548, ISSN 00368075 (doi: 10.1126/science.1136897)

Fricker HA, Scambos T, Carter S, Davis C, Haran T and Joughin I (2010) Synthesizing multiple remote-sensing techniques for subglacial hydrologic mapping: Application to a lake system beneath MacAyeal Ice Stream, West Antarctica. Journal of Glaciology, 56(196), 187-199, ISSN 00221430 (doi: 10.3189/002214310791968557)

Fricker HA, Siegfried MR, Carter SP and Scambos TA (2016) A decade of progress in observing and modeling Antarctic subglacial water systems. Philosophical Transactions of the Royal Society A: Mathematical, Physical and Engineering Sciences, 374(2059), ISSN 1364503X (doi: 10.1098/rsta.2014.0294)

Gardner AS, Moholdt G, Scambos T, Fahnstock M, Ligtenberg S, van den Broeke M and Nilsson J (2018) Increased West Antarctic and unchanged East Antarctic ice discharge over the last 7 years. The Cryosphere, 12(2), 521-547, ISSN 1994-0424 (doi: 10.5194/tc-12-521-2018)

Gillet-Chaulet F, Durand G, Gagliardini O, Mosbeux C, Mouginot J, Rémy F and Ritz C (2016) Assimilation of surface velocities acquired between 1996 and 2010 to constrain the form of the basal friction law under Pine Island Glacier. Geophysical Research Letters, 43(19), 10,311-10,321, ISSN 00948276 (doi: 10.1002/2016GL069937)

Graham FS, Morlighem M, Warner RC and Treverrow A (2018) Implementing an empirical scalar constitutive relation for ice with flow-induced polycrystalline anisotropy in large-scale ice sheet models. The Cryosphere, 12(3), 1047-1067, ISSN 1994-0424 (doi: 10.5194/tc-12-1047-2018)

Haseloff M, Hewitt IJ and Katz RF (2019) Englacial Pore Water Localizes Shear in Temperate Ice Stream Margins. Journal of Geophysical Research: Earth Surface, 124(11), 2521-2541, ISSN 2169-9003 (doi: 10.1029/ 2019JF005399)

Hewitt IJ and Schoof C (2017) Models for polythermal ice sheets and glaciers. The Cryosphere, 11(1), 541-551, ISSN 1994-0424 (doi: 10.5194/tc-11-541-2017)

Hoffman MJ, Catania GA, Neumann TA, Andrews LC and Rumrill JA (2011) Links between acceleration, melting, and supraglacial lake drainage of the western Greenland Ice Sheet. Journal of Geophysical Research: Earth Surface, 116(4), 1-16, ISSN 21699011 (doi: 10.1029/2010JF001934)

Holmes M (2013) Introduction to Perturbation Methods. Springer, New York, NY, 2nd editio edition

Howat IM, de la Peña S, van Angelen JH, Lenaerts JTM and van den Broeke MR (2013) Expansion of meltwater lakes on the Greenland Ice Sheet. The Cryosphere, 7(1), 201-204, ISSN 1994-0424 (doi: 10.5194/tc-7-201-2013)

Hunter P, Meyer C, Minchew B, Haseloff M and Rempel A (2021) Thermal controls on ice stream shear margins. Journal of Glaciology, 1-15, ISSN 0022-1430 (doi: 10.1017/jog.2020.118) 
Iverson NR (2010) Shear resistance and continuity of subglacial till: hydrology rules. Journal of Glaciology, 56(200), 1104-1114, ISSN 0022-1430 (doi: 10.3189/002214311796406220)

Iverson NR and Iverson RM (2001) Distributed shear of subglacial till due to Coulomb slip. Journal of Glaciology, 47(158), 481-488, ISSN 0022-1430 (doi: 10.3189/172756501781832115)

Iverson NR, Hooyer TS and Baker RW (1998) Ring-shear studies of till deformation: Coulomb-plastic behavior and distributed strain in glacier beds. Journal of Glaciology, 44(148), 634-642, ISSN 0022-1430 (doi: 10.1017/ S0022143000002136)

Jacobson HP and Raymond CF (1998) Thermal effects on the location of ice stream margins. Journal of Geophysical Research: Solid Earth, 103(B6), 12111-12122, ISSN 01480227 (doi: 10.1029/98JB00574)

Jezek K, Alley R and Thomas (1985) Rheology of Glacier Ice. Science, 227(4692), 1335-1337, ISSN 0036-8075 (doi: $10.1126 /$ science.227.4692.1335)

Joughin I, MacAyeal DR and Tulaczyk S (2004) Basal shear stress of the Ross ice streams from control method inversions. Journal of Geophysical Research: Solid Earth, 109(B9), n/a-n/a, ISSN 01480227 (doi: 10.1029/ 2003JB002960)

Joughin I, Smith BE and Howat I (2018a) Greenland Ice Mapping Project: Ice flow velocity variation at sub-monthly to decadal timescales. Cryosphere, 12(7), 2211-2227, ISSN 19940424 (doi: 10.5194/tc-12-2211-2018)

Joughin I, Smith BE and Howat IM (2018b) A complete map of Greenland ice velocity derived from satellite data collected over 20 years. Journal of Glaciology, 64(243), 1-11, ISSN 00221430 (doi: 10.1017/jog.2017.73)

Joughin I, Smith BE and Schoof CG (2019) Regularized Coulomb Friction Laws for Ice Sheet Sliding: Application to Pine Island Glacier, Antarctica. Geophysical Research Letters, 46(9), 4764-4771, ISSN 0094-8276 (doi: 10.1029/ 2019GL082526)

Kamb B (1991) Rheological nonlinearity and flow instability in the deforming bed mechanism of ice stream motion. Journal of Geophysical Research, 96(B10), 16585, ISSN 0148-0227 (doi: 10.1029/91JB00946)

King MD, Howat IM, Candela SG, Noh MJ, Jeong S, Noël BPY, van den Broeke MR, Wouters B and Negrete A (2020) Dynamic ice loss from the Greenland Ice Sheet driven by sustained glacier retreat. Communications Earth E Environment, 1(1), 1, ISSN 2662-4435 (doi: 10.1038/s43247-020-0001-2)

Lemos A, Shepherd A, McMillan M, Hogg AE, Hatton E and Joughin I (2018) Ice velocity of Jakobshavn Isbræ, Petermann Glacier, Nioghalvfjerdsfjorden, and Zachariæ Isstrøm, 2015-2017, from Sentinel 1-a/b SAR imagery. Cryosphere, 12(6), 2087-2097, ISSN 19940424 (doi: 10.5194/tc-12-2087-2018)

Livingstone SJ, Clark CD, Woodward J and Kingslake J (2013) Potential subglacial lake locations and meltwater drainage pathways beneath the Antarctic and Greenland ice sheets. Cryosphere, 7(6), 1721-1740, ISSN 19940424 (doi: $10.5194 /$ tc- $7-1721-2013$ )

Lliboutry L (1971) Permeability, Brine Content and Temperature of Temperate Ice. Journal of Glaciology, 10(58), 15-29, ISSN 0022-1430 (doi: 10.3189/s002214300001296x)

Ma Y, Gagliardini O, Ritz C, Gillet-Chaulet F, Durand G and Montagnat M (2010) Enhancement factors for grounded ice and ice shelves inferred from an anisotropic ice-flow model. Journal of Glaciology, 56(199), 805-812, ISSN 0022-1430 (doi: 10.3189/002214310794457209)

MacAyeal DR (1992) The basal stress distribution of Ice Stream E, Antarctica, inferred by control methods. Journal of Geophysical Research, 97(B1), 595, ISSN 0148-0227 (doi: 10.1029/91JB02454)

MacAyeal DR, Bindschadler RA and Scambos TA (1995) Basal friction of Ice Stream E, West Antarctica. Journal of Glaciology, 41(138), 247-262, ISSN 0022-1430 (doi: 10.1017/S0022143000016154) 
Marsh OJ, Fricker HA, Siegfried MR, Christianson K, Nicholls KW, Corr HF and Catania G (2016) High basal melting forming a channel at the grounding line of Ross Ice Shelf, Antarctica. Geophysical Research Letters, 43(1), 250-255, ISSN 19448007 (doi: 10.1002/2015GL066612)

McMillan M, Corr H, Shepherd A, Ridout A, Laxon S and Cullen R (2013) Three-dimensional mapping by CryoSat-2 of subglacial lake volume changes. Geophysical Research Letters, 40(16), 4321-4327, ISSN 00948276 (doi: 10.1002/ $\operatorname{grl} .50689)$

Meyer CR and Minchew BM (2018) Temperate ice in the shear margins of the Antarctic Ice Sheet: Controlling processes and preliminary locations. Earth and Planetary Science Letters, 498, 17-26 (doi: 10.1016/j.epsl.2018. 06.028)

Meyer CR, Fernandes MC, Creyts TT and Rice JR (2016) Effects of ice deformation on Röthlisberger channels and implications for transitions in subglacial hydrology. Journal of Glaciology, 62(234), 750-762, ISSN 0022-1430 (doi: 10.1017/jog.2016.65)

Meyer CR, Yehya A, Minchew B and Rice JR (2018) A Model for the Downstream Evolution of Temperate Ice and Subglacial Hydrology Along Ice Stream Shear Margins. Journal of Geophysical Research: Earth Surface, 123(8), 1682-1698 (doi: 10.1029/2018JF004669)

Millstein JD, Minchew BM, Pegler SS and Sciences P (2021) Reassessing the flow law of glacier oce using satellite observations. (preprint) Communications Earth \& Environment, 1-7

Minchew BM, Meyer CR, Robel AA, Gudmundsson GH and Simons M (2018) Processes controlling the downstream evolution of ice rheology in glacier shear margins: case study on Rutford Ice Stream, West Antarctica. Journal of Glaciology, 64(246), 583-594 (doi: 10.1017/jog.2018.47)

Morlighem M, Seroussi H, Larour E and Rignot E (2013) Inversion of basal friction in Antarctica using exact and incomplete adjoints of a higher-order model. Journal of Geophysical Research: Earth Surface, 118(3), 1746-1753, ISSN 21699003 (doi: 10.1002/jgrf.20125)

Morlighem M, Rignot E, Binder T, Blankenship D, Drews R, Eagles G, Eisen O, Ferraccioli F, Forsberg R, Fretwell P, Goel V, Greenbaum JS, Gudmundsson H, Guo J, Helm V, Hofstede C, Howat I, Humbert A, Jokat W, Karlsson NB, Lee WS, Matsuoka K, Millan R, Mouginot J, Paden J, Pattyn F, Roberts J, Rosier S, Ruppel A, Seroussi H, Smith EC, Steinhage D, Sun B, den Broeke MR, Ommen TD, van Wessem M and Young DA (2020) Deep glacial troughs and stabilizing ridges unveiled beneath the margins of the Antarctic ice sheet. Nature Geoscience, 13(2), 132-137, ISSN 17520908 (doi: 10.1038/s41561-019-0510-8)

Nye J and Frank F (1973) Hydrology of the Intergranular Veins in a Temperate Glacier. Symposium on the Hydrology of Glaciers, $\mathbf{0}(1), 157-161$

Perol T and Rice JR (2015) Shear heating and weakening of the margins of West Antarctic ice streams. Geophysical Research Letters, 42(9), 3406-3413, ISSN 00948276 (doi: 10.1002/2015GL063638)

Perol T, Rice JR, Platt JD and Suckale J (2015) Subglacial hydrology and ice stream margin locations. Journal of Geophysical Research: Earth Surface, 120(7), 1352-1368, ISSN 21699003 (doi: 10.1002/2015JF003542)

Price SF, Payne AJ, Catania GA and Neumann TA (2008) Seasonal acceleration of inland ice via longitudinal coupling to marginal ice. Journal of Glaciology, 54(185), 213-219, ISSN 00221430 (doi: 10.3189/002214308784886117)

Ranganathan M, Minchew B, Meyer CR and Gudmundsson GH (2021a) A new approach to inferring basal drag and ice rheology in ice streams, with applications to West Antarctic Ice Streams. Journal of Glaciology, 67(262), 229-242, ISSN 0022-1430 (doi: 10.1017/jog.2020.95)

Ranganathan M, Minchew B, Meyer CR and Peč M (2021b) Recrystallization of ice enhances the creep and vulnerability to fracture of ice shelves. Earth and Planetary Science Letters, 576, 117219, ISSN 0012821X (doi: 10.1016/j.epsl.2021.117219)

Rignot E, Mouginot J and Scheuchl B (2011) Ice Flow of the Antarctic Ice Sheet. Science, 333(September), 1427-1431 
Robel AA, Degiuli E, Schoof C and Tziperman E (2013) Dynamics of ice stream temporal variability: Modes, scales, and hysteresis. Journal of Geophysical Research: Earth Surface, 118(2), 925-936, ISSN 21699011 (doi: $10.1002 /$ jgrf.20072)

Schoof C (2004) On the mechanics of ice-stream shear margins. Journal of Glaciology, 50(169), 208-218, ISSN 0022-1430 (doi: 10.3189/172756504781830024)

Schoof C and Hewitt IJ (2016) A model for polythermal ice incorporating gravity-driven moisture transport. Journal of Fluid Mechanics, 797, 504-535, ISSN 0022-1120 (doi: 10.1017/jfm.2016.251)

Schroeder DM, Blankenship DD, Young DA and Quartini E (2014) Evidence for elevated and spatially variable geothermal flux beneath the West Antarctic Ice Sheet. Proceedings of the National Academy of Sciences of the United States of America, 111(25), 9070-9072, ISSN 10916490 (doi: 10.1073/pnas.1405184111)

Siegfried MR and Fricker HA (2021) Illuminating Active Subglacial Lake Processes With ICESat-2 Laser Altimetry. Geophysical Research Letters, 48(14), 1-23, ISSN 0094-8276 (doi: 10.1029/2020GL091089)

Siegfried MR, Fricker HA, Roberts M, Scambos TA and Tulaczyk S (2014) A decade of West Antarctic subglacial lake interactions from combined ICESat and CryoSat-2 altimetry. Geophysical Research Letters, 41(3), 891-898, ISSN 19448007 (doi: 10.1002/2013GL058616)

Siegfried MR, Fricker HA, Carter SP and Tulaczyk S (2016) Episodic ice velocity fluctuations triggered by a subglacial flood in West Antarctica. Geophysical Research Letters, 43(6), 2640-2648, ISSN 19448007 (doi: 10.1002/2016GL067758)

Smith EC, Baird AF, Kendall JM, Martín C, White RS, Brisbourne AM and Smith AM (2017) Ice fabric in an Antarctic ice stream interpreted from seismic anisotropy. Geophysical Research Letters, 44(8), 3710-3718, ISSN 19448007 (doi: 10.1002/2016GL072093)

Stearns LA, Smith BE and Hamilton GS (2008) Increased flow speed on a large east antarctic outlet glacier caused by subglacial floods. Nature Geoscience, 1(12), 827-831, ISSN 17520894 (doi: 10.1038/ngeo356)

Stubblefield AG, Creyts TT, Kingslake J, Siegfried MR and Spiegelman M (2021) Surface Expression and Apparent Timing of Subglacial Lake Oscillations Controlled by Viscous Ice Flow. Geophysical Research Letters, 48(17), 1-10, ISSN 19448007 (doi: 10.1029/2021GL094658)

Suckale J, Platt JD, Perol T and Rice JR (2014) Deformation-induced melting in the margins of the West Antarctic ice streams. Journal of Geophysical Research: Earth Surface, 119(5), 1004-1025 (doi: 10.1002/2013JF003008)

Tulaczyk S, Kamb WB and Engelhardt HF (2000a) Basal mechanics of Ice Stream B, West Antarctica: 1. Till mechanics. Journal of Geophysical Research: Solid Earth, 105(B1), 463-481 (doi: 10.1029/1999JB900329)

Tulaczyk S, Kamb WB and Engelhardt HF (2000b) Basal mechanics of Ice Stream B, west Antarctica: 2. Undrained plastic bed model. Journal of Geophysical Research: Solid Earth, 105(B1), 483-494 (doi: 10.1029/1999JB900328)

Turcotte D and Schubert G (2002) Geodynamics. Cambridge University Press

Van Wessem JM, Reijmer CH, Morlighem M, Mouginot J, Rignot E, Medley B, Joughin I, Wouters B, Depoorter MA, Bamber JL, Lenaerts JT, Van De Berg WJ, Van Den Broeke MR and Van Meijgaard E (2014) Improved representation of East Antarctic surface mass balance in a regional atmospheric climate model. Journal of Glaciology, 60(222), 761-770, ISSN 00221430 (doi: 10.3189/2014JoG14J051) 